\title{
COUPLED ANALYSIS OF A BACKFILL HYDRATION TEST
}

\author{
E. E. ALONSO ${ }^{1 *}$, A. LLORET ${ }^{1}$, C. H. DELAHAYE ${ }^{1}$, J. VAUNAT ${ }^{1}$, A. GENS ${ }^{1}$ AND G. VOLCKAERT ${ }^{2}$ \\ ${ }^{1}$ E.T.S. de Ingenieros de Caminos, Canales y Puertos, Technical University of Catalunya, 08034 Barcelona, Spain \\ ${ }^{2}$ SCK-CEN, Boeretang 200, B-2400 Mol. Belgium
}

\begin{abstract}
SUMMARY
BACCHUS2 in situ isothermal wetting experiment has been analysed by means of a coupled flowdeformation approach. Backfill material, a mixture of Boom clay powder and high density pellets, has been extensively tested in the laboratory in order to determine its hydraulic and mechanical properties. Parameters of constitutive equations were derived from this experimental data base. Two mechanical constitutive models have been used in the simulation of the 'in situ' experiment: a state surface approach and an elastoplastic model. Calculations have shown several features of the hydration process which help to understand the behaviour of expansive clay barriers. Predictions using both models have been compared with each other and with actual measurement records. This has allowed a discussion of the comparative mertis of both approaches and the identification of some critical parameters of backfill behaviour. Overall agreement between calculations and field measurements is encouraging and shows the potential of the methods developed to model the behaviour of engineered clay barriers in the context of nuclear waste disposal. (C) 1998 by John Wiley \& Sons, Ltd.
\end{abstract}

Int. J. Numer. Anal. Meth. Geomech., Vol. 22, 1-27 (1998)

(No. of Figures: 20 No. of Tables: 2 No. of Refs: 19)

Key words: expansive clay; hydromechanics; unsaturated soils; nuclear waste; in situ test

\section{INTRODUCTION}

Compacted clays are adopted as appropriate engineered barriers in design concepts which consider the placement of the nuclear waste canisters in deep geological formation other than salt (clay, marl, granite). Very active clays (bentonites) or compacted mixtures of clay powder and high-density clay pellets have been suggested as suitable materials. Once installed in contact with the (usually saturated) natural host rock these barriers experience: (a) a transient wetting phase governed by the rate of absorption of natural water and (b) a transient temperature regime controlled by the decaying heat power input induced by the canister. The process is complex since parts of the barrier in the proximity of the hot canisters will be initially dried, whereas the outer boundary of the compacted barrier will surely hydrate and expand. The host rock close to the clay buffer will also experience a transient drying-wetting phase as the natural clay first loses water towards the unsaturated compacted fill and later resaturates. Stresses will be controlled by the relatively low initial stress state of the compacted buffer, the development of shrinkage and swelling strains and the stiffness of the backfill and surrounding host rock. Temperature changes

* Corresponding to E. E. Alonso, E.T.S. de Ingenieros de Caminos, Canales y Puertos, Technical University of Catalunya, 08034 Barcelona, Spain

CCC 0363-9061/98/010001-27\$17.50

Received 30 March 1995

(C) 1998 by John Wiley \& Sons, Ltd.

Revised 4 April 1997 
are also coupled with hydrothermal phenomena in several ways (water vapour transfer is strongly dependent on temperature and it also influences permeability, water retention and mechanical properties). In summary, a number of inter-related processes affect the clay buffer and host rock. The time length of this phase and its potential effects in modifying or conditioning some of the key properties of the barrier (such as its tightness) are difficult to predict. For this reason a number of large-scale 'in situ' hydration experiments such as BACCHUS2, performed in the HADES underground research laboratory located in Mol, Belgium, and excavated in the Miocene plastic Boom clay at $220 \mathrm{~m}$ depth, have been carried out. These tests provide useful data for the validation of models but, for practical reasons, only a limited period of the hydration process is monitored. From a basic, fundamental type of view this initial phase is characterized by the unsaturated nature of the compacted clay barrier.

In this paper the coupled hydro-mechanical behaviour of a clay barrier will be analysed in connection with the BACCHUS2 experiment. In contrast with the previous discussion, no heat source was used in BACCHUS2 and therefore the analysis reported here is isothermal.

Two alternative mechanical analyses of the in situ test will be presented in the paper. The first analysis is based on the concept of state surface as a convenient way to describe clay volumetric deformations in terms of changes of mean stress and suction. This approach has several limitations (irreversible and path-dependent effects cannot be modelled and neither the effect of suction changes in deviatoric strains, nor the influence of deviatoric stresses on volumetric changes induced by suction changes are considered). However, it has proved useful to model

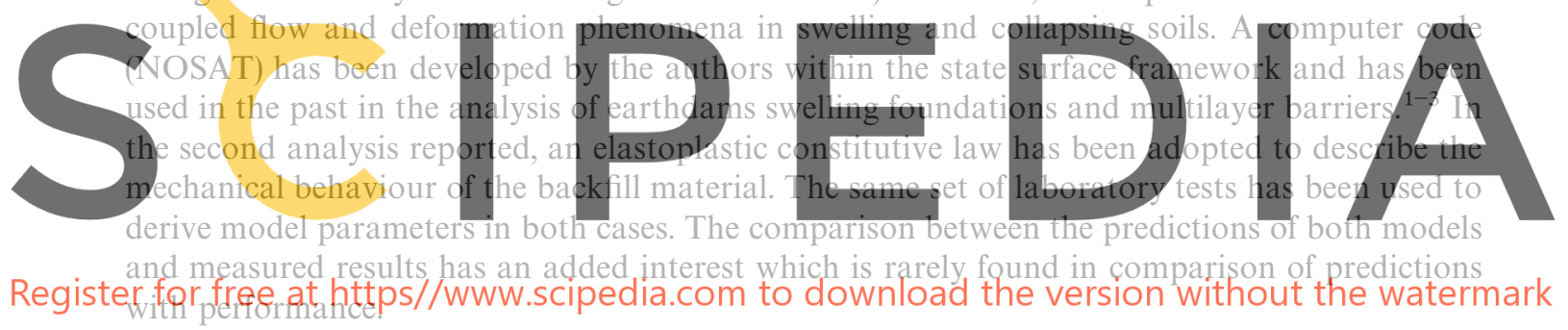

\section{THEORETICAL BASIS}

The isothermal flow-deformation problem in an unsaturated soil requires the solution of the following governing equations:

water mass balance

$$
\frac{\partial\left(\rho_{\mathrm{w}} n S_{\mathrm{r}}\right)}{\partial t}+\operatorname{div}\left(\rho_{\mathrm{w}} \mathbf{v}_{\mathrm{w}}\right)=0
$$

air mass balance

$$
\frac{\partial}{\partial t}\left[\rho_{\mathrm{a}} n\left(1-S_{\mathrm{r}}+H S_{\mathrm{r}}\right)\right]+\operatorname{div}\left[\rho_{\mathrm{a}}\left(\mathbf{v}_{\mathrm{a}}+H \mathbf{v}_{\mathrm{w}}\right)\right]=0
$$

equilibrium equations

$$
\frac{\partial}{\partial x_{j}}\left(\sigma_{i j}-\delta_{i j} p_{\mathrm{a}}\right)+\frac{\partial p_{\mathrm{a}}}{\partial x_{i}}+b_{i}=0
$$


where $\rho_{\mathrm{w}}, \rho_{\mathrm{a}}$ are mass densities of water and air; $\mathbf{v}_{\mathrm{w}}$ and $\mathbf{v}_{\mathrm{a}}$ water and air (Darcy) velocities; $n$ porosity; $S_{\mathrm{r}}$ degree of saturation; $H$ Henry's constant; $\left(\sigma_{i j}-\delta_{i j} p_{\mathrm{a}}\right)$ net stresses (i.e. the excess of total stress, $\sigma_{i j}$, over air pressure, $p_{\mathrm{a}}$ ).

Note that when suction is zero, air and water pressures become equal and equation (3) becomes the equilibrium equation in terms of effective stresses. This situation applies, initially, to the saturated natural clay.

Flow of water and air is assumed to be governed by generalized Darcy's laws. Permeabilities are assumed to vary with suction and void ratio according to

$$
\begin{gathered}
K_{\mathrm{w}}\left(e, S_{\mathrm{r}}\right)=K_{\mathrm{w}}^{o} /\left(1+A s^{B}\right) \\
K_{\mathrm{a}}\left(e, S_{\mathrm{r}}\right)=C \frac{\gamma_{\mathrm{a}}}{\mu_{\mathrm{a}}}\left[e\left(1-S_{\mathrm{r}}\right)\right]^{D}
\end{gathered}
$$

where $K_{\mathrm{w}}^{0}$ is the water permeability for saturated conditions, $s$ is the matric suction $\left(s=p_{\mathrm{a}}-p_{\mathrm{w}}\right)$; $\gamma_{\mathrm{a}}$ specific weight of air; $\mu_{\mathrm{a}}$ air viscosity; $e$ void ratio and $A, B, C, D$ parameters.

It is also required to specify the water retention characteristics of the soil. The following variation of degree of saturation with suction has been adopted in the analysis: ${ }^{4}$

$$
S_{\mathrm{r}}=0.995-E(1-\exp (-s F))
$$

where $E, F$ are constants

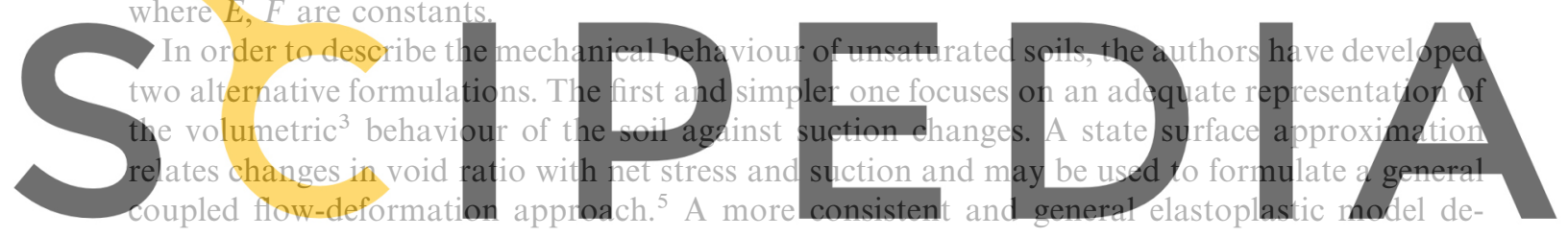

scribes important features of unsaturated soil behaviour such as irreversibility of strains, joint

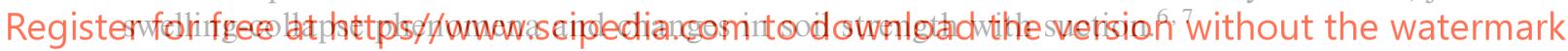

The two approaches will be outlined below.

\subsection{State surface approach}

A convenient way to formulate the stress-strain relationship under the state surface framework is to consider the volumetric strains induced by suction changes as initial thermal-like strains:

$$
\mathrm{d} \sigma_{i j}^{*}=D_{i j k l}\left(\mathrm{~d} \varepsilon_{k l}-\mathrm{d} \varepsilon_{o} \delta_{k l}\right)
$$

where $\sigma_{i j}^{*}=\sigma_{i j}-\delta_{i j} p_{\mathrm{a}}$ are the net stresses and $\mathrm{d} \varepsilon_{o}$ are the suction-induced volumetric strains. They are given by an empirical expression relating void ratio and changes in net mean stress and suction. Based on the analysis of several suction controlled experimental programs, the following equation has been proposed: ${ }^{8}$

$$
e=d+a \log \left(\sigma-p_{\mathrm{a}}\right)+b \log \left(s+p_{\mathrm{at}}\right)+c \log \left(\sigma-p_{\mathrm{a}}\right) \log \left(s+p_{\mathrm{at}}\right)
$$

where $a, b, c, d$ are constants, $\sigma$ the mean total stress and $p_{\text {at }}$ the atmospheric pressure. For small changes of stress and suction linearized expressions may also be suitable:

$$
e=d^{\prime}+a^{\prime}\left(\sigma-p_{\mathrm{a}}\right)+b^{\prime}\left(s+p_{\mathrm{at}}\right)+c^{\prime}\left(\sigma-p_{\mathrm{a}}\right)\left(s+p_{\mathrm{at}}\right)
$$


In the analysis presented here, coefficients of the matrix $D$ correspond to an isotropic non-linear elastic model defined by a compressibility modulus, $K_{t}$, and a shear modulus, $G_{t}$. $K_{t}$ is obtained directly from (7) or (8) by differentiation:

$$
\frac{1}{K_{t}}=\frac{1}{1+e_{o}} \frac{\mathrm{d} e}{\mathrm{~d}\left(\sigma-p_{\mathrm{a}}\right)}
$$

$G_{t}$ is obtained from $K_{t}$, through a constant Poisson's ratio. This implies that the shear modulus varies also with the current net mean confining stress in a way similar to $K_{t}$.

\subsection{Elastoplastic model}

Under triaxial stress states $(p, q, s)$ where $p$ is the net mean stress $\left[p=\left(\sigma_{1}+2 \sigma_{3}\right) / 3-p_{\mathrm{a}}\right], q$ is the deviatoric stress $\left(q=\sigma_{1}-\sigma_{3}\right)$ and $s$ the matric suction the model postulates a yield function given by the following family of ellipses:

$$
q^{2}-M^{2}\left(p+p_{s}\right)\left(p_{o}-p\right)=0
$$

In this equation $p_{s}$ is related to the increase in apparent cohesion with suction and is given by

$$
p_{s}=k_{s} s
$$

and $p_{0}$ is the current yield stress for isotropic stress conditions and is related to the applied suction
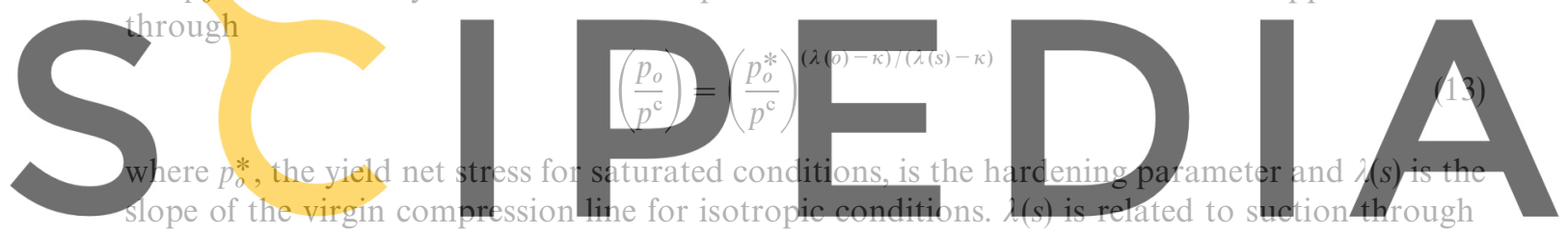

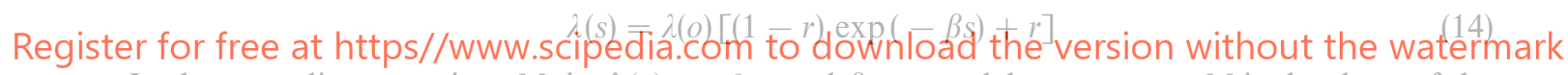

In the preceding equation, $M, k_{s}, \lambda(0), \kappa, p^{\mathrm{c}}, r$ and $\beta$ are model parameters. $M$ is the slope of the critical state line, $\lambda(0)$ is the slope of the virgin compression line for saturated conditions, $\alpha$ is the slope of the (elastic) isotropic unloading-reloading paths and $p^{c}$ is a reference stress. $r$ defines the compression index at high suctions and $\beta$ provides the rate of change of $\lambda(s)$ with $s$.

It is assumed in the model that hardening is controlled by the plastic volumetric strains $\left(\mathrm{d} \varepsilon_{v}^{\mathrm{p}}\right)$ through

$$
\frac{\mathrm{d} p_{o}^{*}}{p_{o}^{*}}=\frac{v}{\lambda(o)-\kappa} \mathrm{d} \varepsilon_{v}^{\mathrm{p}}
$$

where $v=1+e$ is the specific volume.

A non-associated flow rule relating shear $\left(\mathrm{d} \varepsilon_{q}^{\mathrm{p}}\right)$ and volumetric deformations $\left(\mathrm{d} \varepsilon_{v}^{p}\right)$ was adopted:

$$
\frac{\mathrm{d} \varepsilon_{q}^{\mathrm{p}}}{\mathrm{d} \varepsilon_{v}^{\mathrm{p}}}=\frac{2 q \alpha}{M^{2}\left(2 p+p_{s}-p_{o}\right)}
$$

where $\alpha$ is a constant related to $M, \kappa$ and $\lambda(o)$. Volumetric and deviatoric elastic strains induces by stress $(p, q)$ and suction $(s)$ changes inside the yield locus are given by

$$
\mathrm{d} \varepsilon_{v}^{\mathrm{e}}=\frac{\kappa}{v} \frac{\mathrm{d} p}{p}
$$




$$
\begin{gathered}
\mathrm{d} \varepsilon_{q}^{\mathrm{e}}=\frac{G}{3} \mathrm{~d} q \\
\mathrm{~d} \varepsilon_{s}^{\mathrm{e}}=\kappa_{s} \frac{\mathrm{d} s}{s+p_{\mathrm{at}}}
\end{gathered}
$$

where $\kappa_{s}$ is the compressibility modulus against suction changes and $G$ the constant shear stiffness.

This model reproduces expansive and collapse deformations but has some limitations for highly expansive materials. A double structure model, which is a modification of the previously outlined framework, is able to reproduce better specific features of behaviour of those materials. ${ }^{9}$ In this paper, however, the basic form of the elastoplastic model will be used in the simulation of the 'in situ' BACCHUS2 test.

\section{DESCRIPTION OF THE BACCHUS2 TEST}

The experimental set-up is shown in Figure 1. A bottom steep plate (diameter: $475 \mathrm{~mm}$; thickness $50 \mathrm{~mm}$ ) welded to an instrumented central $\operatorname{ram}(\phi=80 \mathrm{~mm})$ was lowered into the bottom of a large diameter shaft $(\phi=490-540 \mathrm{~mm})$ drilled from the floor of the HADES underground research tunnel located at $220 \mathrm{~m}$ depth in overconsolidated Boom clay. The shaft reaches a

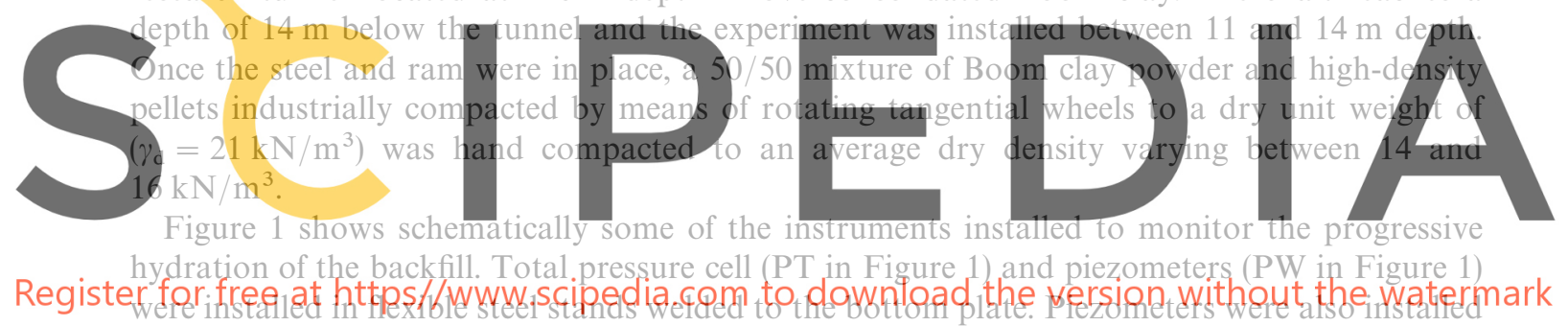

on the surface of the central ram. This ram was prepared to act as a filter/drain for incoming water and, alternatively as a water injector. In fact, during the first phase of the test (October 1993-November 1994) the fill was hydrated from the natural clay. A second phase started in November 1994, in which water was injected through the central ram. This paper refers only to the first natural hydration phase.

The progress of hydration was monitored by carrying out thermal probe tests. The distribution of temperatures induces by a heat pulse was measured by means of a network of thermocouple sensors installed across the fill. The heat pulse induced by a central probe lasted $5 \mathrm{~d}$ and was carried out at constant electric power $(120 \mathrm{~W}$ at the beginning of the test when the fill was dry and $140 \mathrm{~W}$ at the end of the experiment when the backfill was saturated). When the fill was dry the maximum temperature rise varied from $45^{\circ} \mathrm{C}$ close to the heater to $30-32^{\circ} \mathrm{C}$ at the interface with the natural clay. This temperature range changed to $35-30^{\circ} \mathrm{C}$ when the fill was saturated. These transient temperature changes are believed to induce very small thermo-hydro-mechanical changes in the fill. In fact, after the cooling phase readings of the instrumentation (pore water and total pressure transducers) remained within the current trend of changes. More details may be found in. ${ }^{10}$ Back calculated thermal conductivity values at several radial positions have been converted into moisture contents and degrees of saturation by means of a correlation obtained in the laboratory. 


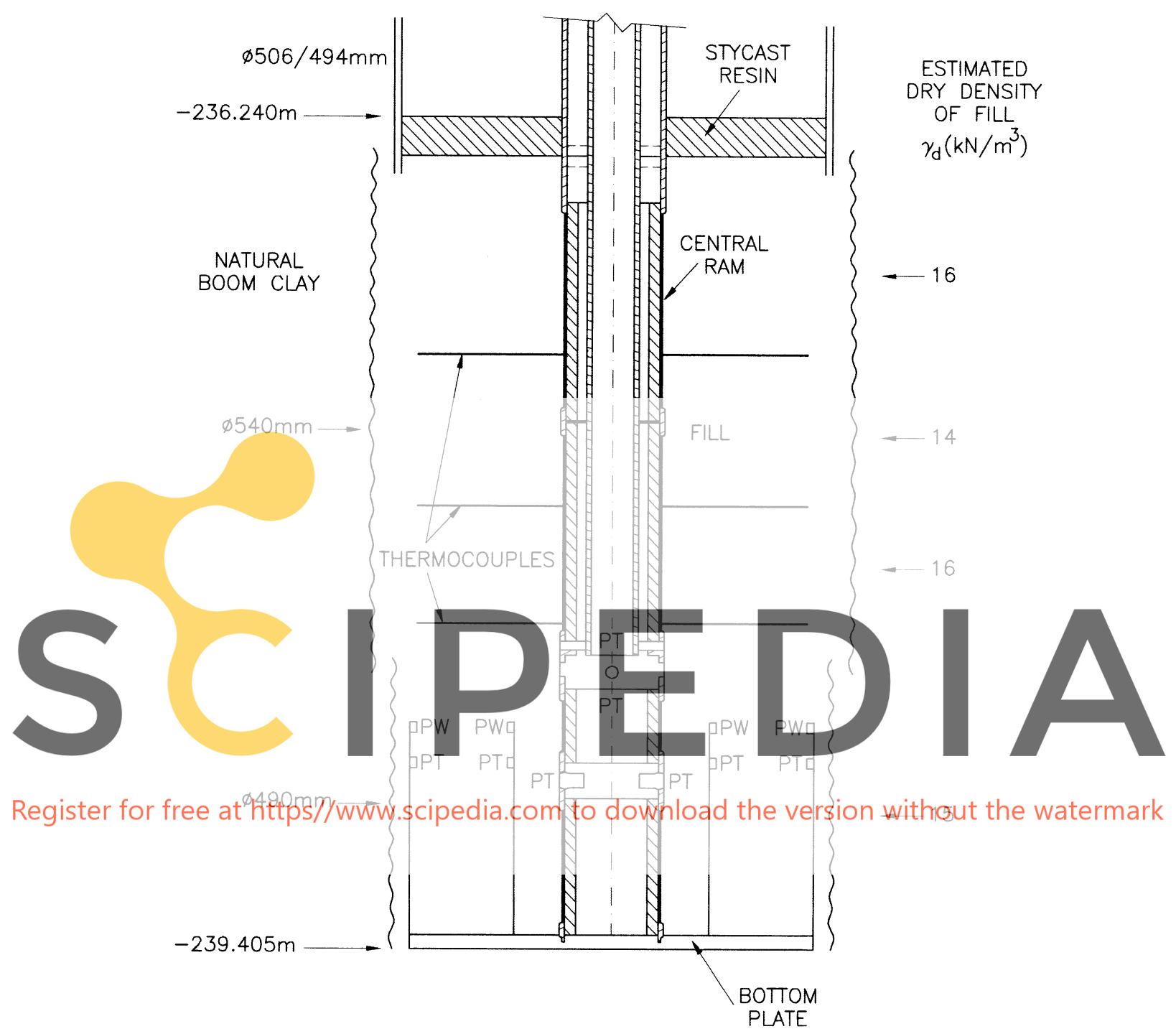

TRANSDUCERS : PT : TOTAL PRESSURE

PW: PORE WATER PRESSURE

Figure 1. BACCHUS2 experiment (Reference 10)

The host clay is also instrumented in the vicinity of the hydration test. Temperature, total and pore water pressures and humidity measurements (by means of a neutron probe) can be performed at different radial distances. ${ }^{11}$ 


\section{BOUNDARY AND INITIAL CONDITIONS}

Axisymmetric and plain strain conditions in a central horizontal plane have been assumed in the analysis. The geometry is indicated in Figure 2: a central rigid cylinder $(\phi=80 \mathrm{~mm})$ is in contact with the backfill. The interface between natural clay and compacted soil is a $0.5 \mathrm{~m}$ diameter cylinder. Boundary conditions, as specified below, have been imposed, in the natural clay, in an outer cylinder, $7 \cdot 0 \mathrm{~m}$ in a diameter.

Initial conditions for the hydration test have been established by means of a simulation of the actual operations: excavation of the shaft and compaction of the backfill mixture.

The sequence of calculations performed to determine initial stress conditions is indicated schematically in Figure 3. The initial state of stress in the host natural clay was derived from
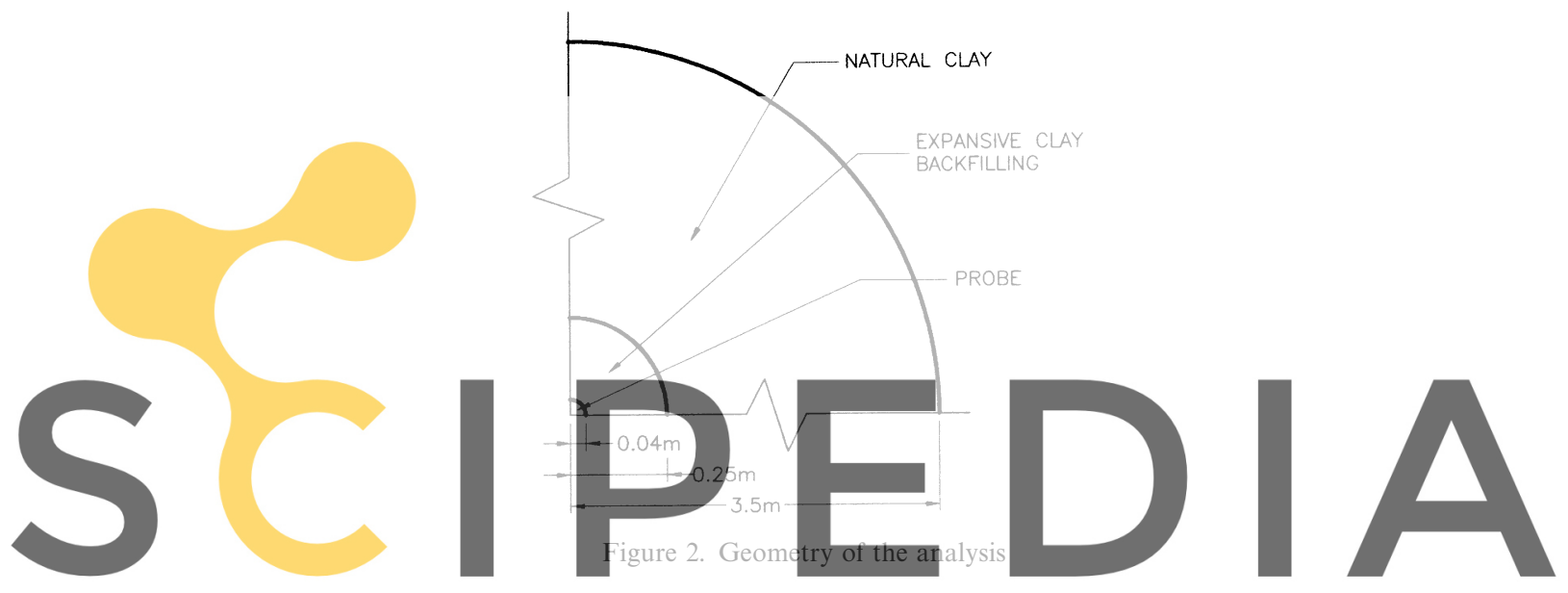

Register for free at https//www.scipedia.com to download the version without the watermark
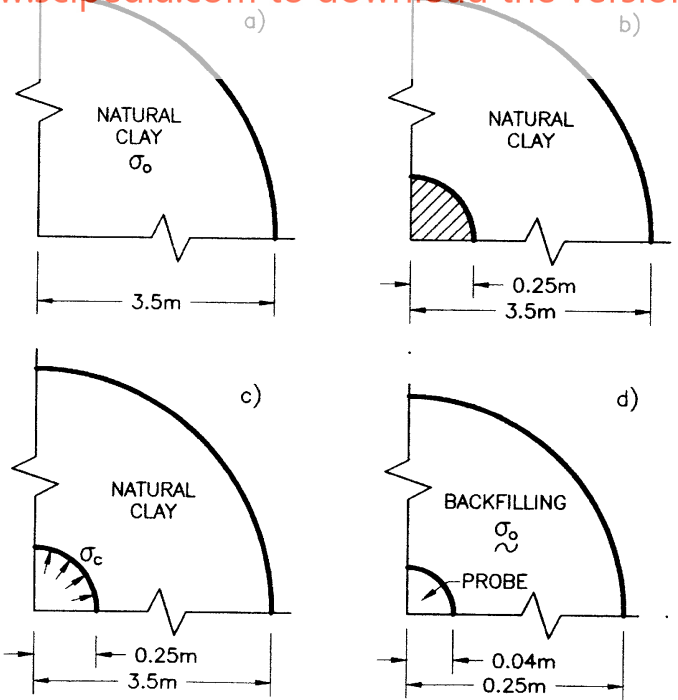

Figure 3. Simulation of initial conditions. (a) initial state. (b) borehole drilling. (c) backfill compaction. (d) final state 
'in situ' measurements. Based on those results, an almost isotropic stress state (total horizontal stress, $\sigma_{o \mathrm{~h}}=2.02 \mathrm{MPa}$; total vertical stress, $\sigma_{o \mathrm{v}}=1.9 \mathrm{MPa}$ was assumed). The large excavation $(\phi=500 \mathrm{~mm})$ (Figure 3(b)) modifies the initial state of stress in the natural Boom clay and allows the installation of the test set up. Then, the effect of compaction of the backfill is simulated by means of a small horizontal stress $\left(\sigma_{o}=0.05 \mathrm{MPa}\right)$ (Figures 3(c) and 3(d)). The initial suction of the fill was taken as $60 \mathrm{MPa}$ according to the initial degree of saturation and the measured water retention curve. ${ }^{12}$

A zero displacement and impervious boundary (for both water and air) was imposed at the radius $r=3.50 \mathrm{~m}$. Computed results showed that during the whole transient phase of the experiment significant changes of mechanical and hydraulic variable took place within a radius not exceeding $1 \mathrm{~m}$. The selected outer boundary remains in a zone essentially unchanged by the presence of the experiment. Mixed boundary conditions were prescribed on the surface of the steel cylinder: if the fill tends to move inwards zero displacement is imposed. However, if the backfill moves outwards a zero stress condition is assumed. A drain-type condition was adopted in this probe/backfill content: the boundary is impervious unless the water pressure becomes positive in the vicinity of the contact. In this case, a zero pressure boundary is imposed.

\section{SOIL PARAMETERS}

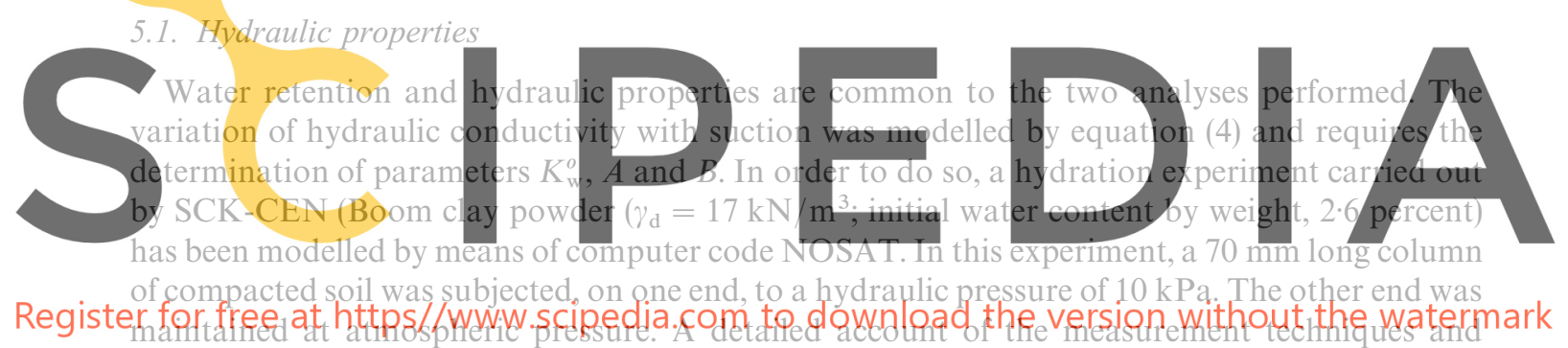

results is given in. ${ }^{12}$ Water content was periodically monitored at close intervals by means of an X-ray tomographic technique. Measured results are given in Figure 4. Water intake by the sample was also measured and modelled (Figure 5). The best agreement was found for the set of parameters given in Table I (backfill). Based on laboratory permeability tests, a different permeability for saturated conditions was adopted for the natural clay. However, variation with suction was kept identical in both materials.

Variation of air conductivity with suction was based on measurements of relative gas conductivity carried out by SCK-CEN within MEGAS project. ${ }^{13}$ The air conductivity was measured by a pulse test technique. Parameters $C$ and $D$ of equation (5) are also given in Table I. Finally, retention curves were based on laboratory determinations of the variation of degree of saturation with suction for a sample of Boom clay powder compacted at a dry unit weight, $\gamma_{\mathrm{d}}=17 \mathrm{kN} / \mathrm{m}^{3}$. Measured points and the adopted analytical relationship are shown in Figure 6. Parameters $E$ and $F$ of equation (6) are given in Table I.

\subsection{Mechanical parameters}

State surface approach. Wetting tests carried out in conventional and suction controlled oedometer devices on compacted samples of Boom clay powder and pellets provided the data for 


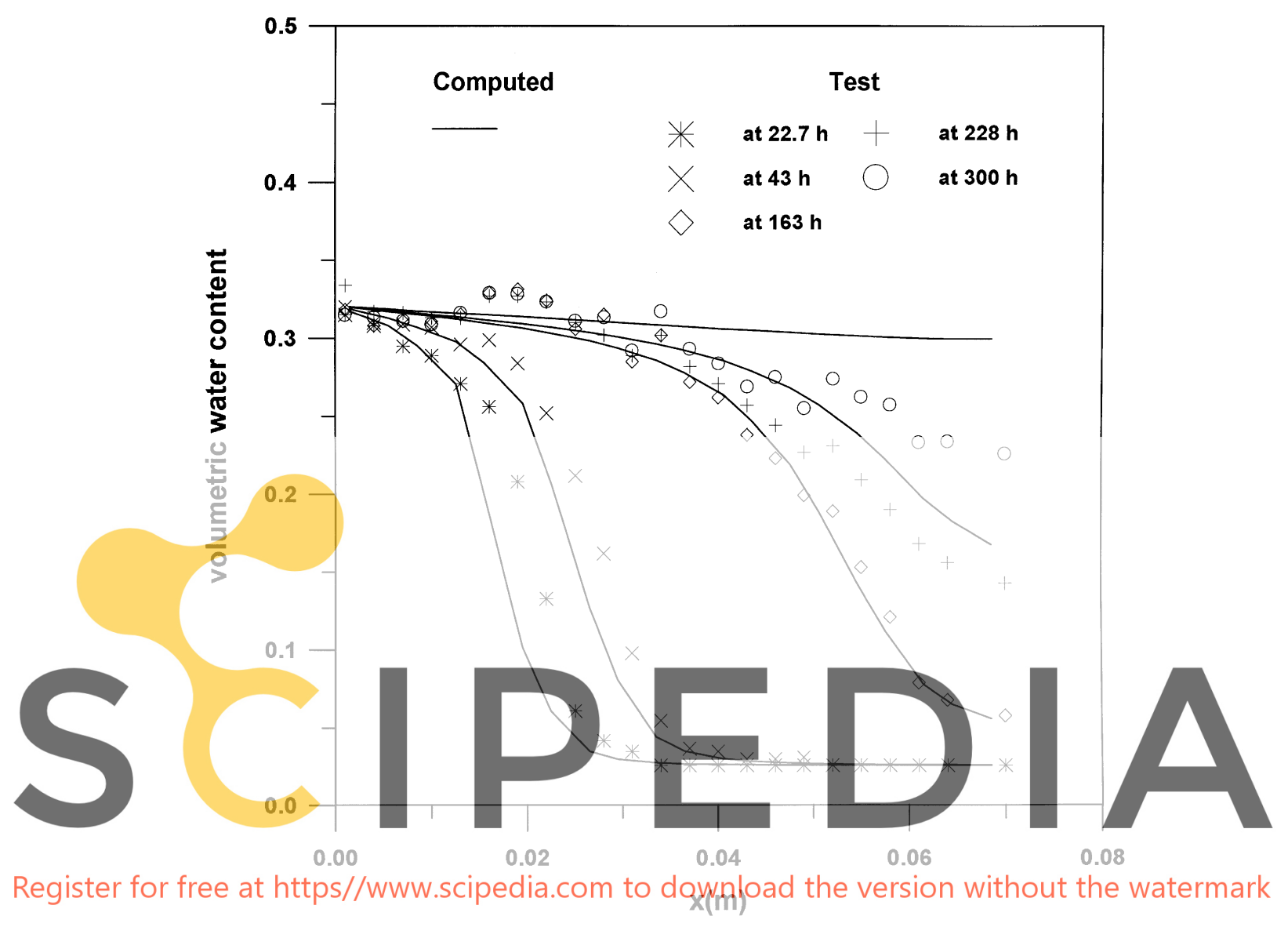

Figure 4. Comparison between measured and estimated evolution of water content aiong the specimen in the hydration experiment

parameter determination. Tests performed in conventional oedometers involved a single step wetting of samples from its initial as-compacted state. In suction-controlled oedometers a large reduction in suction was first applied from the high initial value to a suction close to $0.5 \mathrm{MPa}$. Further wetting was then controlled in steps by reducing nitrogen pressure. Vertical loads in the range $0-1000 \mathrm{kPa}$ were applied in combination with the mentioned suction changes. A least squares techniques was used to minimize the differences between calculations, as given by equation (8), and measured strains. The optimum state surface is plotted in Figure 7 and the parameters are given in Table II. The adopted surface predicts a swelling strain of 15.7 percent when the fill is wetted under a vertical stress of $10 \mathrm{kPa}$. The vertical stress which prevents any swelling when the soil is saturated is $440 \mathrm{kPa}^{12}$. A ring of natural clay close to the interface with the unsaturated compacted fill is first partially dried as water is sucked into the fill. Eventually, it saturates again as saturation of the fill progresses. This transient shrinkage-wetting episode experienced by the natural clay was also modelled with a state surface. Drying tests performed in samples compacted to $\gamma_{\mathrm{d}}=17 \mathrm{kN} / \mathrm{m}^{3}$ and in situ measured values of shear modulus 


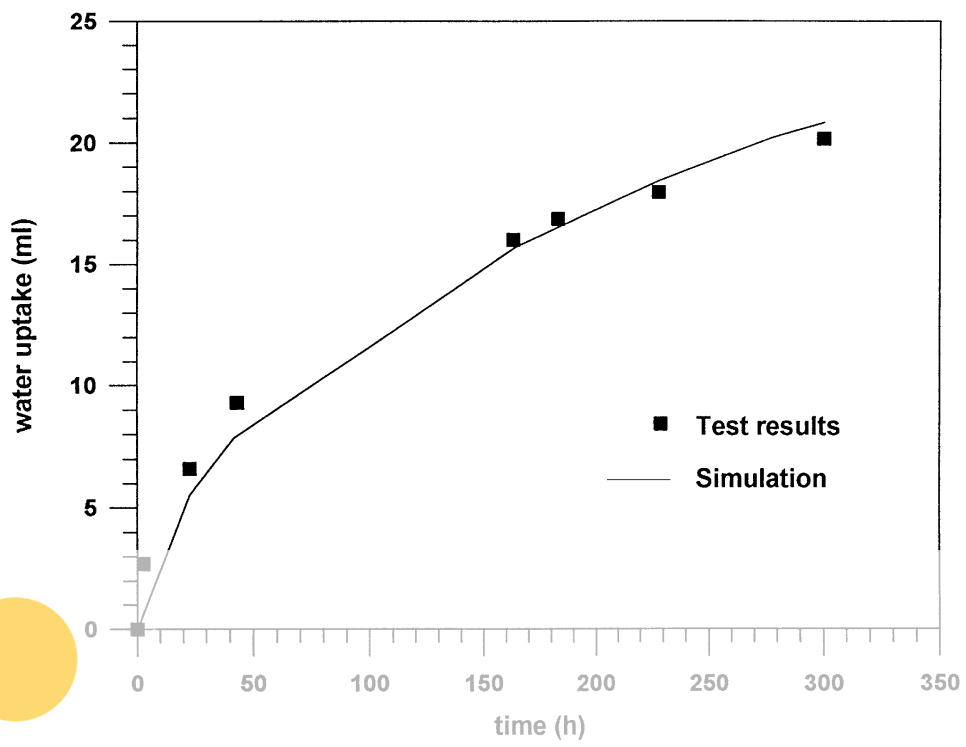

Figure 5. Comparison between measured and estimated evolution of water uptake in hydration experiment
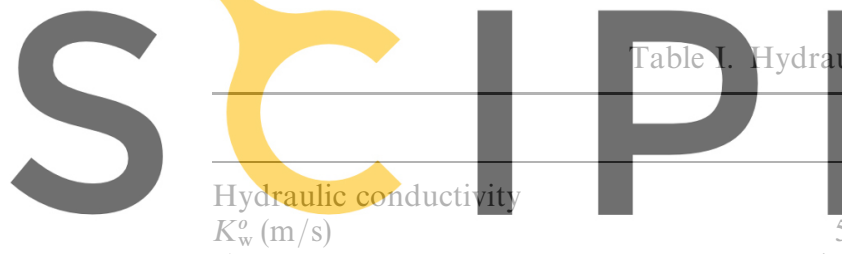

Register for

$5 \times 10$
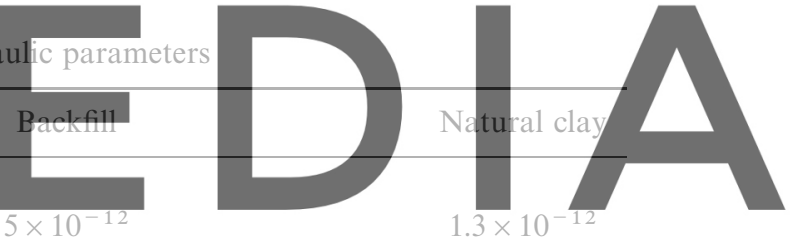

de.boload the version withoutsthe watermark

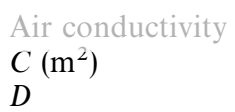

Water retention

E

$F(\mathrm{k} \mathrm{Pa})$
$1.53 \times 10^{-16}$

$2 \cdot 47$

0.918

$8.61 \times 10^{-5}$
$1.31 \times 10^{-19}$

$2 \cdot 47$

0.918

$8.61 \times 10^{-5}$

$(G=150 \mathrm{MPa})$ have been used to approximate a simplified state surface given by equation (9). In situ $G$ values and state of stress were derived from self-boring pressuremeter tests (Cambridge apparatus) performed in $1988 .{ }^{14,15}$ Parameters are given in Table II.

Elastoplastic approach. Model parameters have been determined on the basis of laboratory tests and also on additional information concerning the 'in situ' testing and stress monitoring. A detailed presentation of the methodology for parameter determination is beyond the scope of this paper. ${ }^{12}$ The procedure followed to obtain some relevant parameters of elastoplastic model will, however, be outlined. The set of parameters which control the change in virgin soil stiffness with suction $(\lambda(o) ; r ; \beta)$ may be obtained if compression tests under different suctions are 


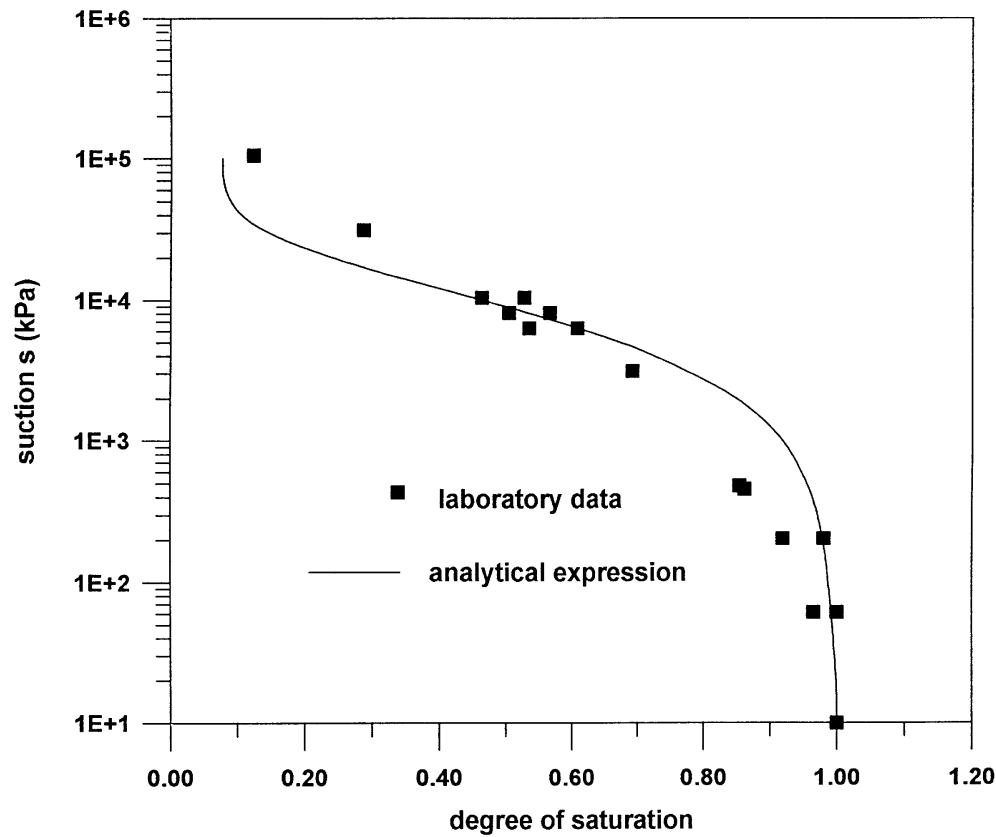

Figure 6. Water retention relationship. Comparison between analytical expression and laboratory data

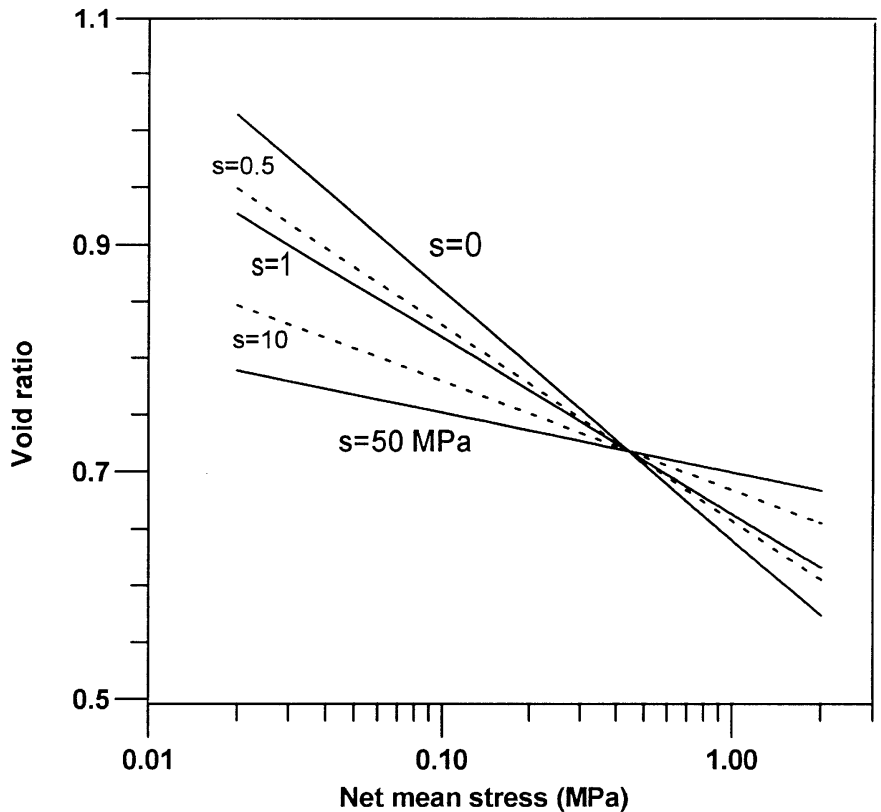

Figure 7. State surface for void ratio 
Table II. Mechanical parameters

\begin{tabular}{lcc}
\hline & Backfill & Natural clay \\
\hline State surface for void ratio $(s, \sigma$ in $\mathrm{Pa})$ & $3 \cdot 71$ & \\
$d$ & $-0 \cdot 53$ & 0.66 \\
$a$ & $-0 \cdot 35$ & -0.008 \\
$b$ & $0 \cdot 062$ & -0.00275 \\
$c$ & $0 \cdot 3$ & $0 \cdot 3$ \\
$v$ & & \\
Elastoplastic model & $9 \cdot 5 \times 10^{-3}$ & $2 \cdot 65 \times 10^{-2}$ \\
$\kappa$ & $9 \cdot 3 \times 10^{-2}$ & $2 \cdot 6 \times 10^{-1}$ \\
$\lambda(0)$ & $1 \times 10^{-2}$ & $3.22 \times 10^{-3}$ \\
$\kappa_{s}$ & 60 & 60 \\
$p^{c}(\mathrm{kPa})$ & $0 \cdot 564$ & 0.564 \\
$r$ & $5.44 \times 10^{-2}$ & $5.44 \times 10^{-2}$ \\
$\beta(\mathrm{kPa})$ & $0 \cdot 3$ & 0.333 \\
$v$ & 1 & 1 \\
$M$ & $7 \cdot 32 \times 10^{-3}$ & $7.32 \times 10^{-3}$ \\
$k_{s}$ & & \\
\hline
\end{tabular}

performed. Two of such tests are shown in Figure 8. They provide the values: $\lambda(s=0)=0 \cdot 093$; $\lambda(s=450 \mathrm{kPa})=0.0525$. A third test for $s=10 \mathrm{kPa}, \lambda(s=10 \mathrm{kPa})=0.076$ is used to find $r$ and $\beta$ by solving a non-linear equation system (recall equation (14)).

A yield stress $p_{0}^{*}=120 \mathrm{kPa}$ could be approximated from saturated compression tests for a dry unit weight $\gamma_{\mathrm{d}}=16 \mathrm{kN} / \mathrm{m}^{3}$ (see also Figure 8). Yield stresses are always difficult to pinpoint accurately and a comparison with measured stresses suggested that a higher value $\left(p_{0}^{*}=150 \mathrm{kPa}\right)$ improved the agreement. An explanation for this apparent backfill preconsolidation stress is the compaction process followed during test installation. See also the final discussion of Section 6.2.

Basic stiffness parameters for the natural clay were based on existing information on Boom clay. ${ }^{14,15}$ However, due to a lack of suction controlled tests on the natural clay, the variation of stiffness and strength with suction was maintained equal for the fill and the host clay. The set of model parameters used in calculations is given in Table II.

\section{ANALYSIS, COMPARISON WITH FIELD MEASUREMENTS}

\subsection{Flow regime}

The state surface approach and elastoplastic approach lead essentially to the same hydraulic results. This is illustrated in Figure 9 which shows the evolution of negative pore water pressures for three points inside the backfill. The small differences between program NOSAT (state surface approach) and B1R (elastoplastic approach) may be explained by the different type of integration rule used in the two programs. The mechanical constitutive model does not affect the flow pattern in this case. The evolution of measured values of degree of saturation, at three different radial distances (South direction) determined by means of the heat pulse technique is compared in Figure 10 with calculated values using the elastoplastic analysis (the state surface approach leads to similar values). It was realized that, probably due to heterogeneities in the host clay and/or the backfill, the fill hydration proceeded more slowly in the North direction. Obviously, the analysis 


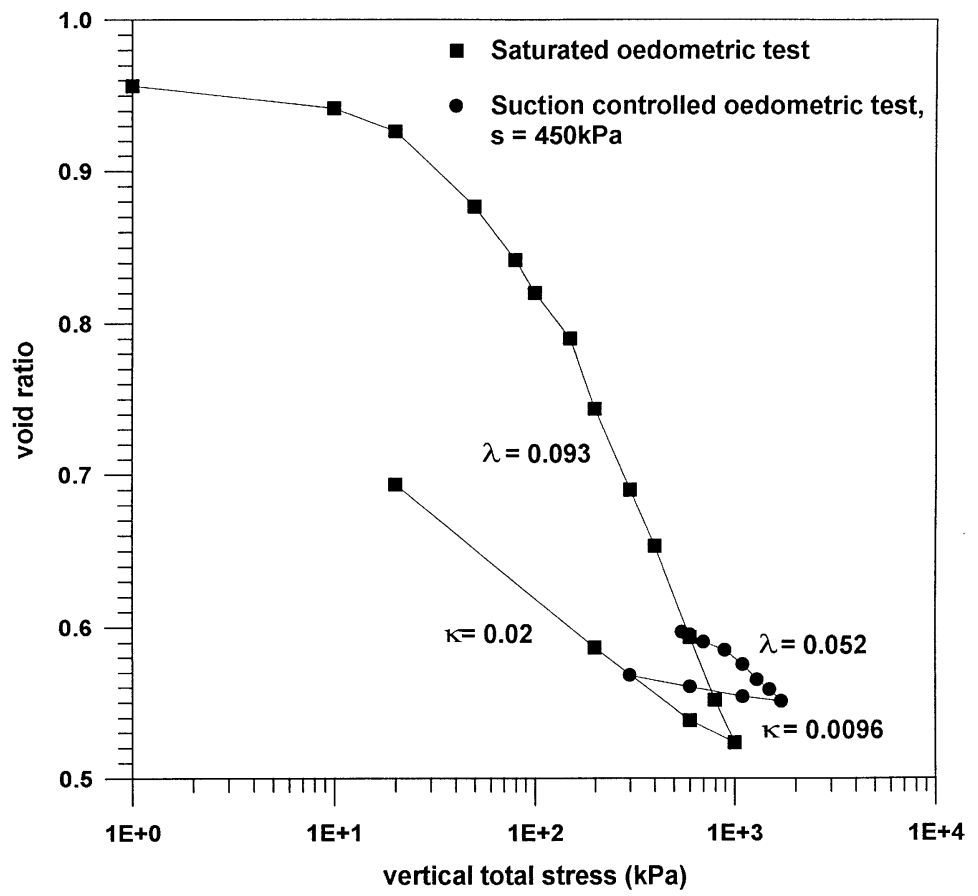

Figure 8. Compression curves for $s=0$ and $s=450 \mathrm{kPa}$. Compacted Boom clay powder at $\gamma_{\mathrm{d}}=17 \mathrm{kN} / \mathrm{m}^{3}$

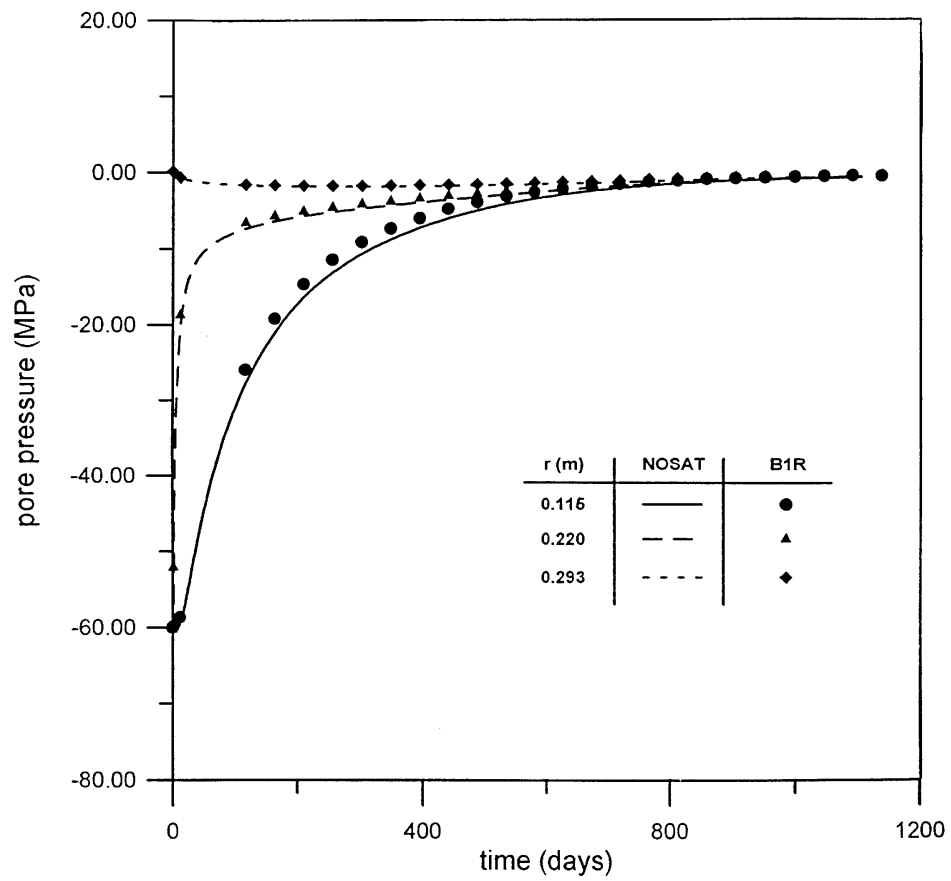

Figure 9. Time history of water pressure at three selected points using state surface and elastoplastic approach 


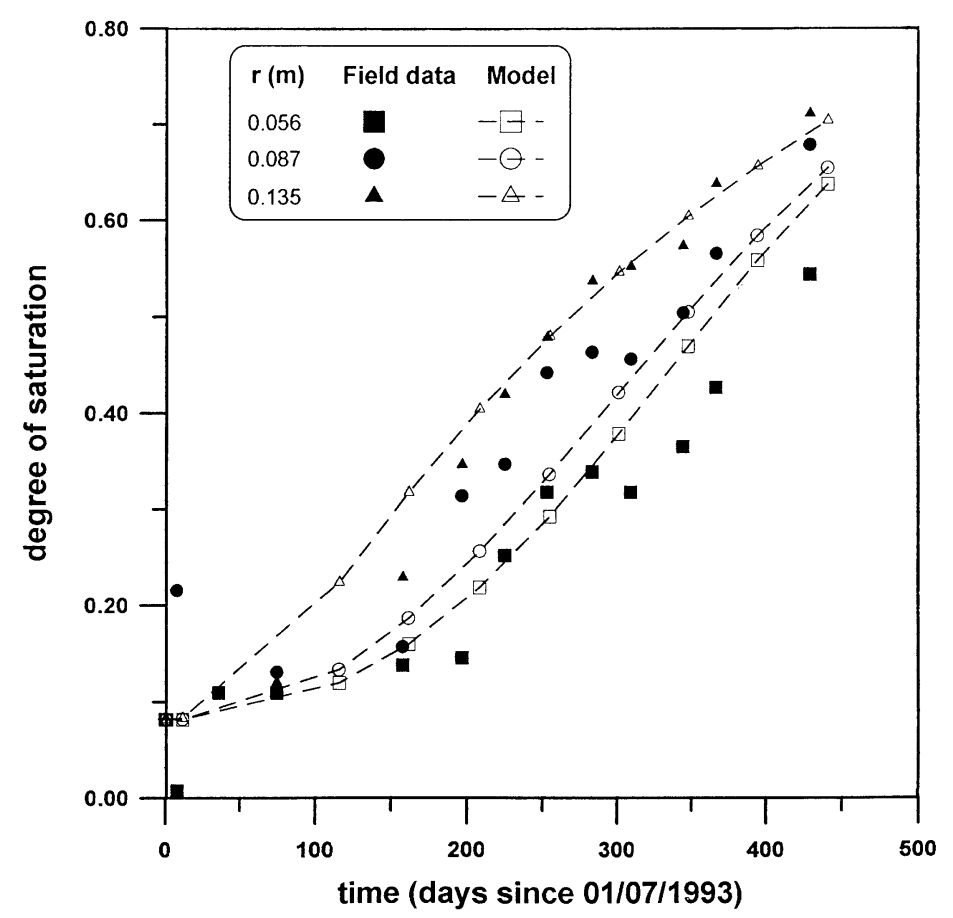

Figure 10. Measured and calculated evolution of degree of saturation of backfill for three different radial coordinates. South direction

performed, which assumes axisymmetry, is not able to reproduce this behaviour. The agreement shown in Figure 10 is, however, quite significant and the small observed differences are within the range of measurement errors.

\subsection{Mechanical behaviour}

Immediately after the fill is compacted in place, water is pulled from the natural clay due to the high initial suction of the compacted clay. The outer ring of the backfill swells and compacts the inner zones and the natural clay. This behaviour is illustrated in Figures 11(a) and 11(b) for the state surface (s.s.) and elastoplastic (e.p.) analysis, respectively. Volumetric strain is plotted in terms of time for a few radial distances. The point closest to the interface with the host rock experiences in both analysis a rapid swelling and compresses inner zones (and the surrounding host clay). As time increases, significant qualitative differences between the two types of analysis develop. For instance, the e.p. analysis predicts a relatively constant volumetric expansion of the outer ring of the backfill whereas in the s.s. analysis compressive volumetric strains are computed in this outer ring once the maximum expansion is reached at an early stage. In both analyses, the initially compressed points in the central zones of the backfill experience a volumetric expansion as the saturation front progresses inwards

These changes are reflected in the computed radial displacements (Figure 12). The s.s. analysis predicts an initial inward displacement of the backfill and neighbouring points in the natural clay. 

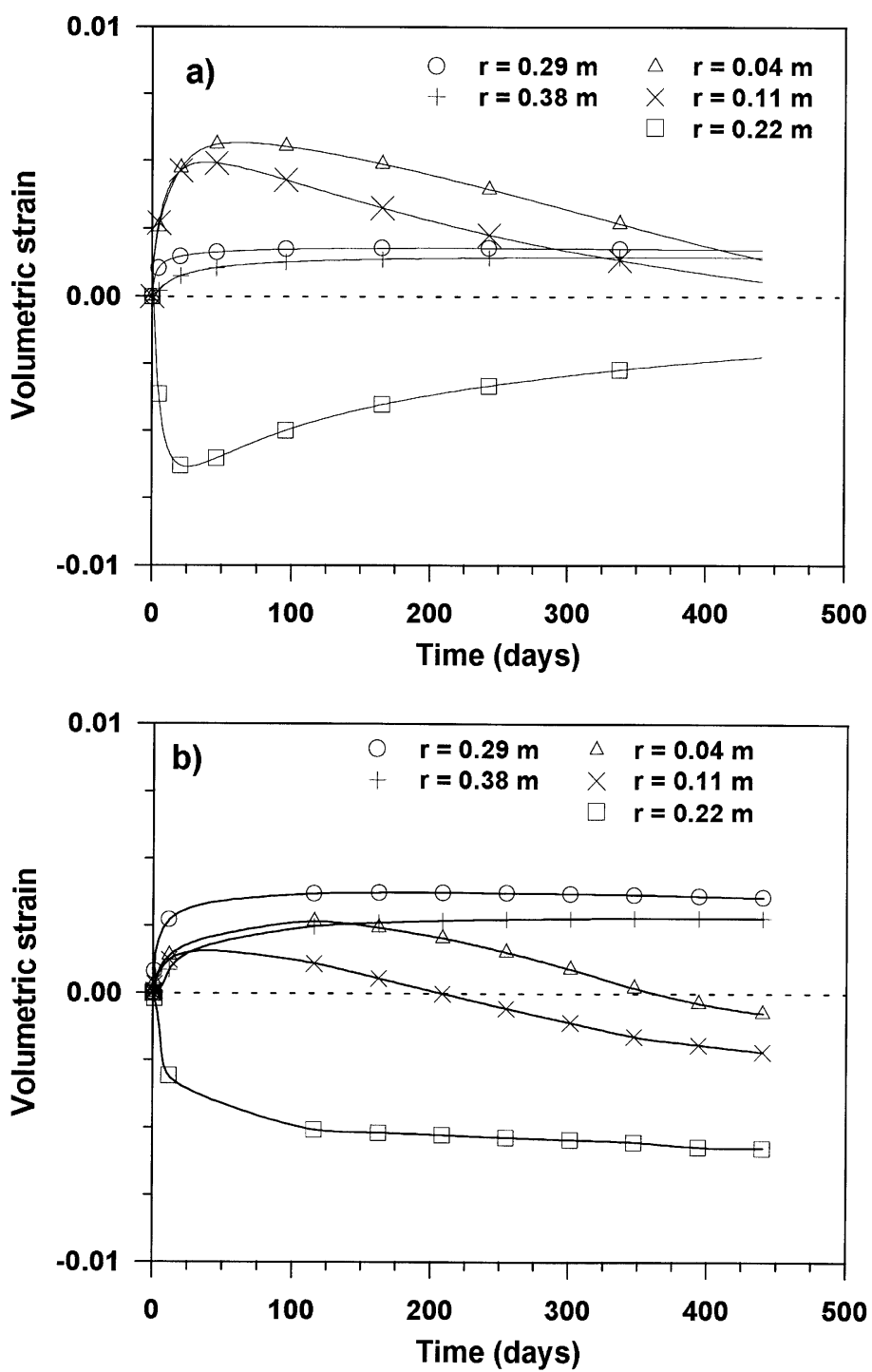

Figure 11. Evolution of volumetric strain in the backfill for different radial coordinates. (a) State surface approach. (b) Elastoplastic approach

This is probably due to a decrease in fill stiffness induced by the rapid changes in suction. It takes some time before the fill expansion is able to offset the initial inward displacement. The e.p. analysis shows more marked outward displacement of the outer backfill ring as time increases. Eventually, all the backfill exhibits an outward displacement. No separation between the central steel shaft and the backfill is computed in both analyses. It is clear from these comments that the stiffness changes of the backfill and the relative stiffness of natural clay and backfill dictates the distribution and direction of displacements, which seems to be a very sensitive variable. Differences between s.s. and e.p. analysis are also explained if one considers the stiffness changes 

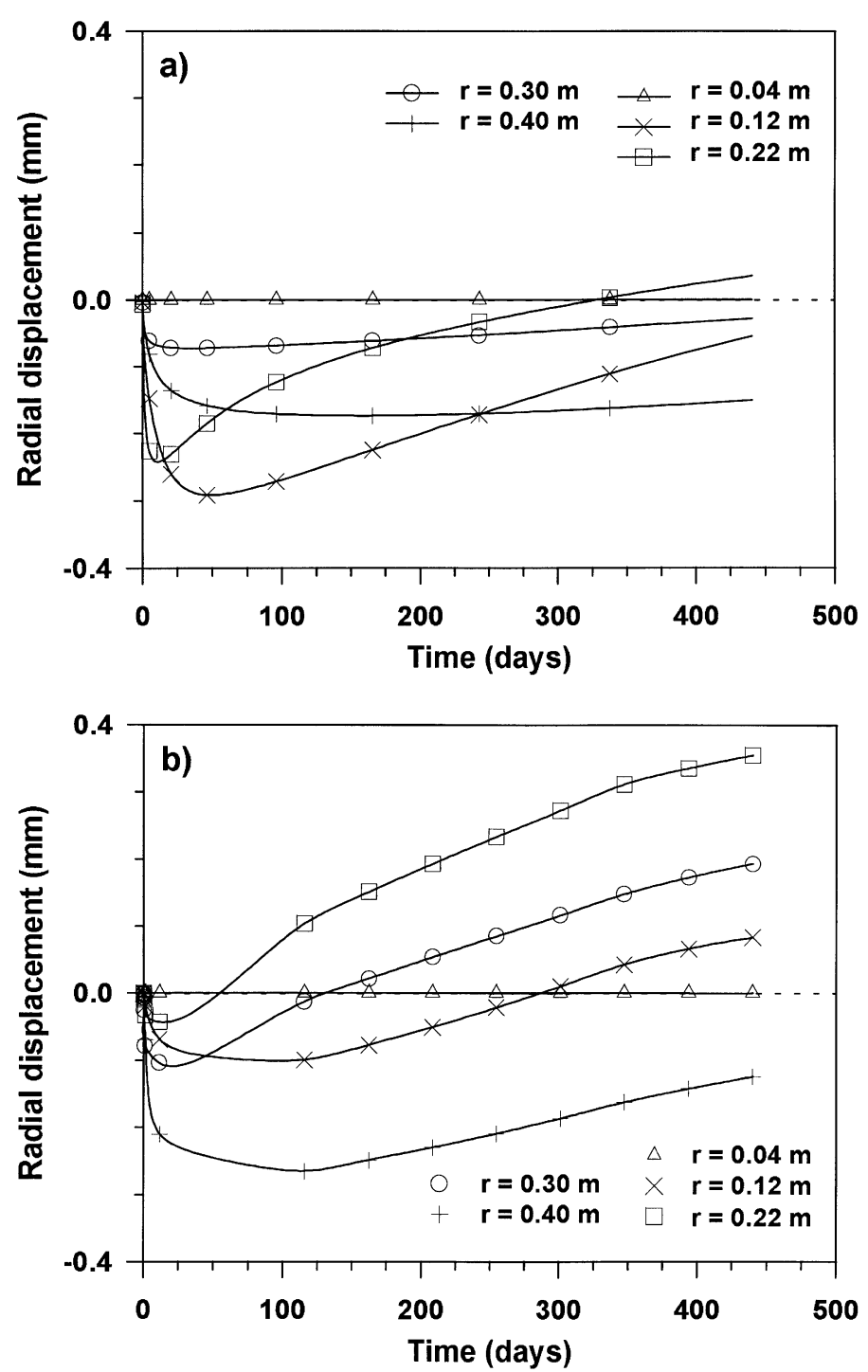

Figure 12. Evolution of radial displacements. (a) s.s. approach. (b) e.p. approach

in both models. Within the s.s. approach any change in average net stress or suction results in a parallel change of soil stiffness. Under the e.p. framework the (elastic) stiffness parameters remain constant irrespective of loading and suction changes, provided the stress path lies within the current yield surface. This important qualitative difference provides an explanation for some discrepancies between calculations carried out with both models.

Radial stresses (Figure 13) are, however, relatively homogeneous within the fill and experience a continuous increase in time. Larger values are computed under the e.p. approach. Similar results are obtained for the mean net stress. 

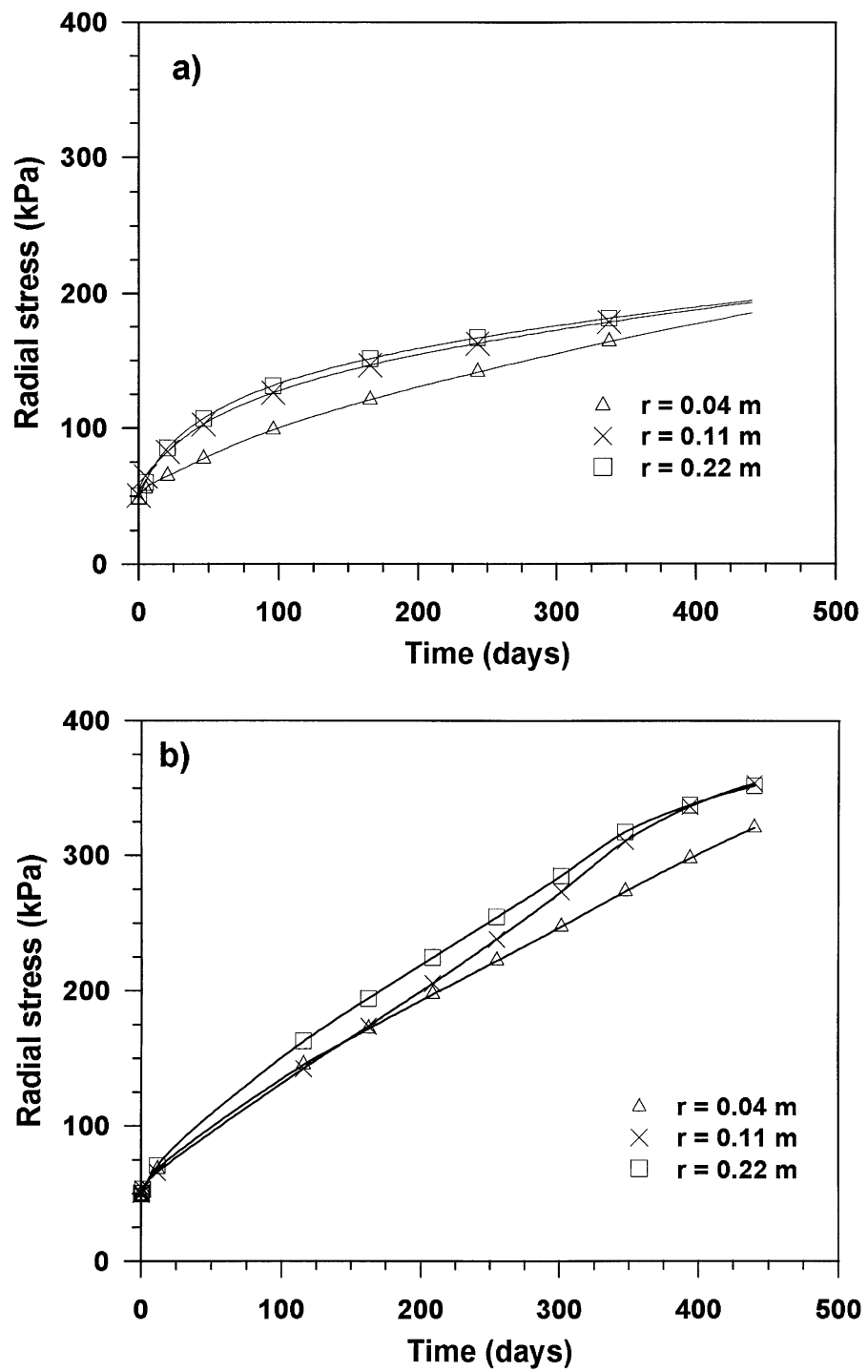

Figure 13. Evolution of radial stresses in the backfill for different radial coordinates. (a) s.s. approach. (b) e.p. approach

Stress paths in both $(p, s)$ and $(p, q)$ planes provide an accurate image of the processes experienced by points of the backfill and host clay as the hydration process develops. Consider first in Figure 14 the stress paths of the backfill in the $(p, s)$ plane. The plotted paths are typical swelling pressure type of paths: as suction decreases, confining pressures increase. All the points within the fill experience a qualitatively similar behaviour. Consider, however, in Figure 15 the $(p, s)$ stress paths for two points of the natural clay close to the backfill interface. The initial fill-induced dessication implies a reduction in net mean stress. In the long term, the clay regains saturation (suction decreases again) as the mean stress increases. 

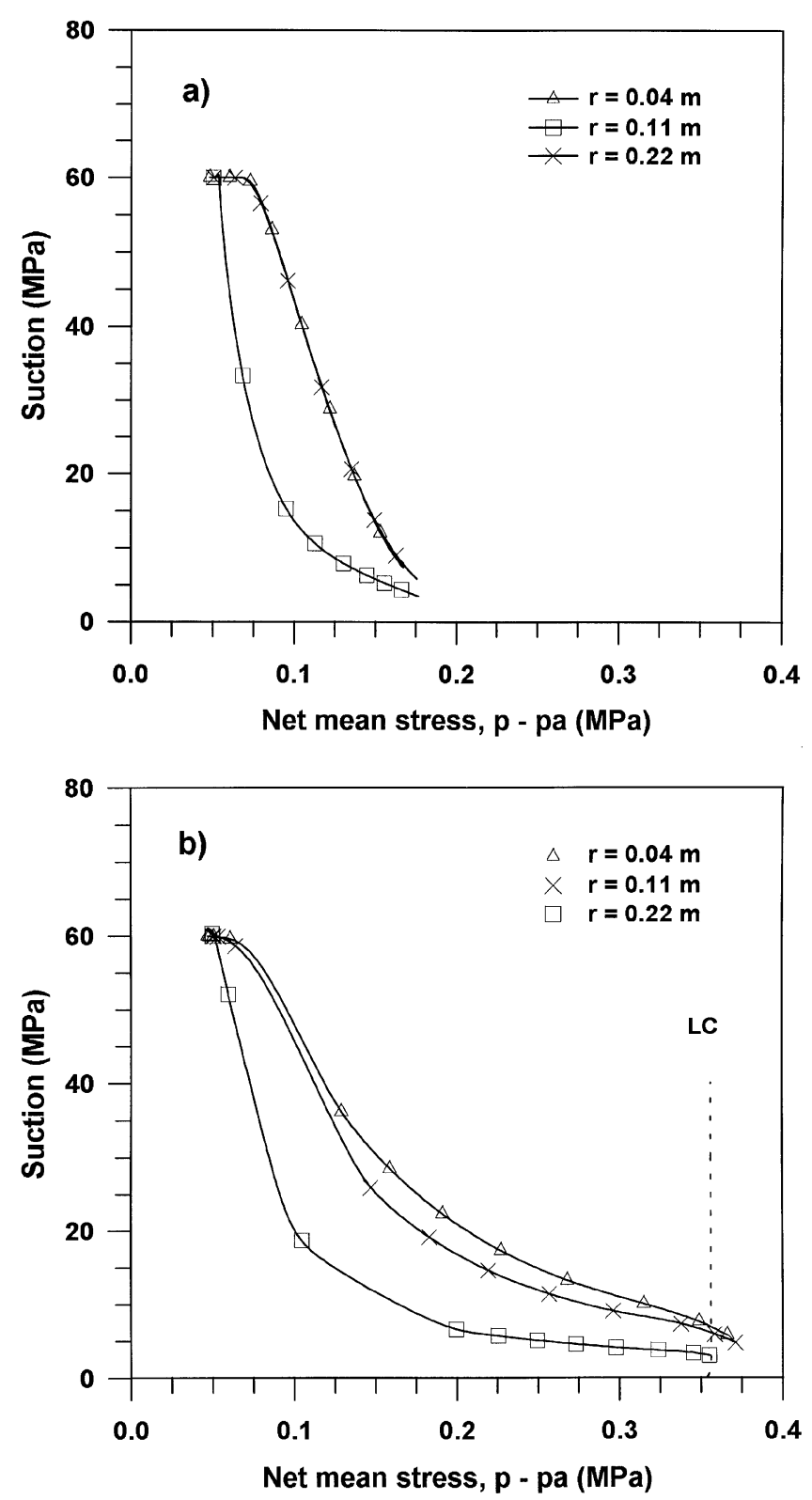

Figure 14. Stress paths in ( $p, s)$ plane for points of the backfill. (a) s.s. approach. (b) e.p. approach

Stress paths in $(p, q)$ plane demonstrate that the process is relatively complex (Figure 16). In both approaches a steady increase in net mean stress is found although shear stress reversals are also computed. Points near the centre of the backfill maintain states close to hydrostatic conditions whereas the maximum deviatoric stresses are found at the backfill boundaries. 


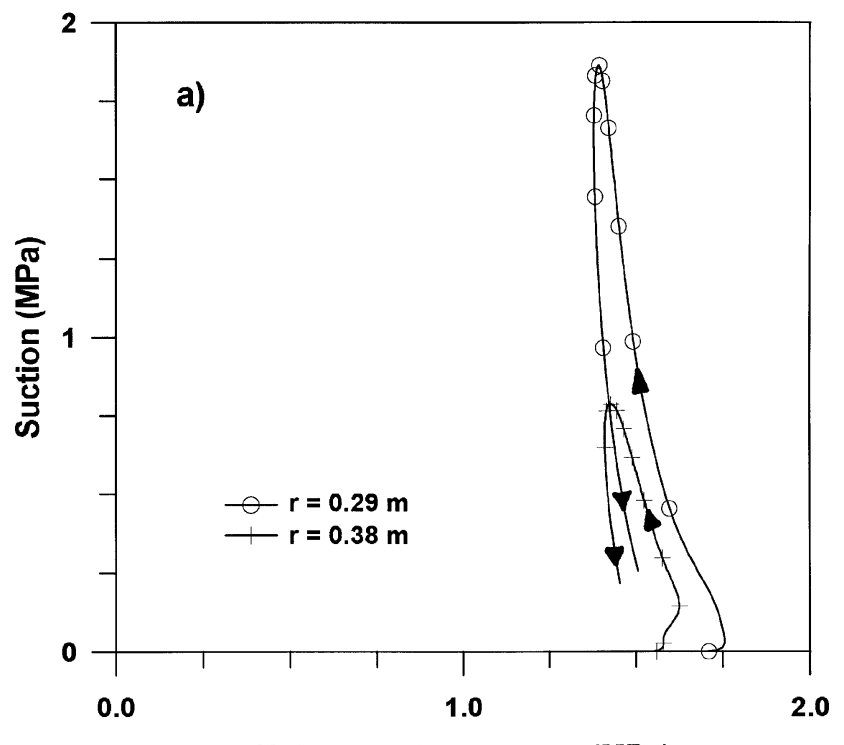

Net mean stress, $\mathrm{p}-\mathrm{pa}(\mathrm{MPa})$

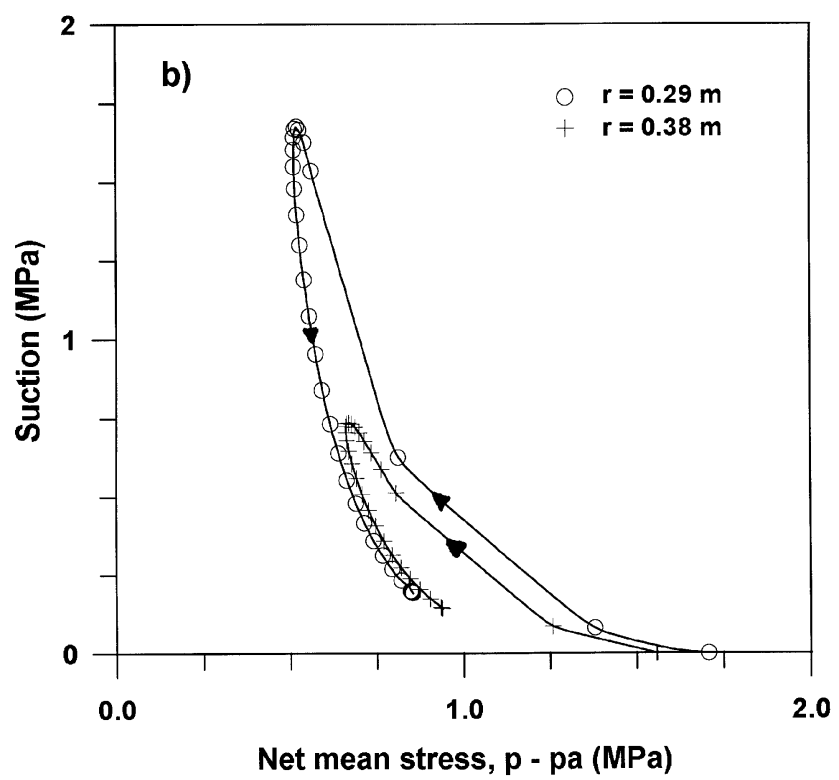

Figure 15. Stress paths in $(p, s)$ plane for points in the natural clay close to the interface. (a) s.s. approach. (b) e.p. approach

Measured radial stresses at two positions within the backfill $(r=0.22 \mathrm{~m}$ and $r=0.11 \mathrm{~m})$ are compared with computations in Figures 17 and 18 respectively. Field data exhibits a marked scatter when stresses along North and South directions are compared. The state surface approach predicts a rapid early development of stresses and a continuous decrease in the rate of stress 


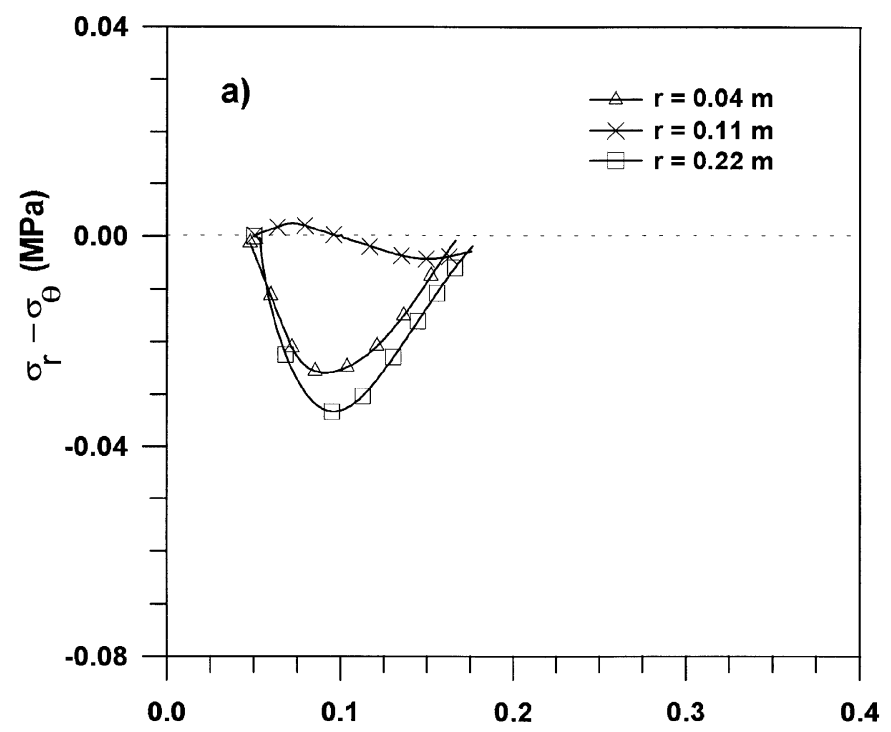

Net mean stress, $\mathrm{p}$ - pa (MPa)

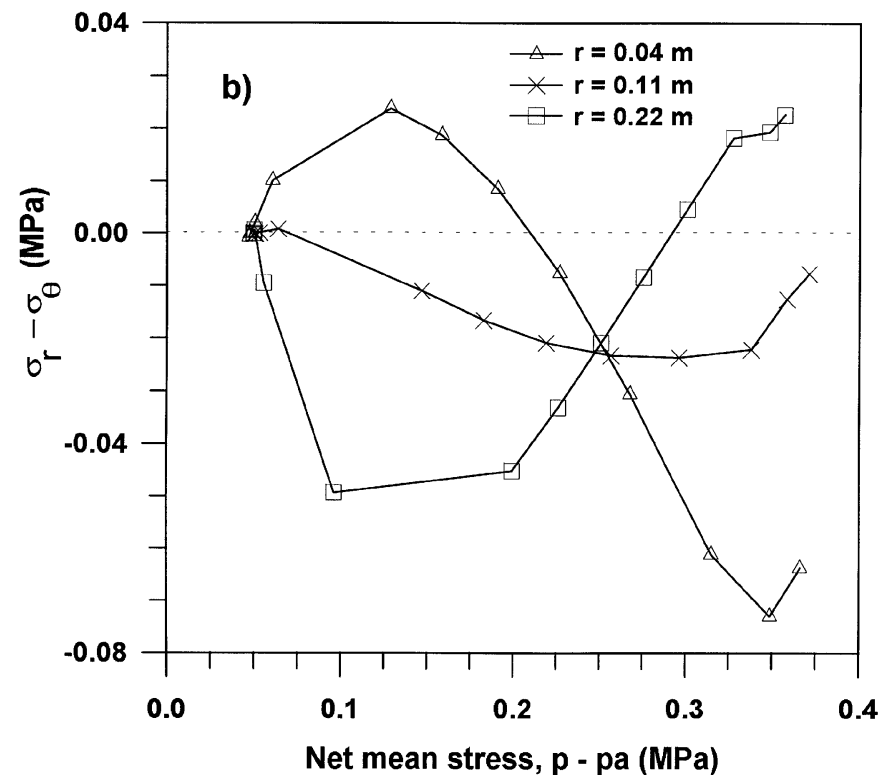

Figure 16. Stress paths in $(p, q)$ plane for points within the backfill. (a) s.s. approach. (b) e.p. approach

development. In this way, it overestimates all the measurements at the beginning of the hydration period and tends to underestimate the lowest values of measured stresses (North direction) at larger times. This behaviour is linked with the continuous decrease of soil stiffness as suction reduces implied by the state surface approach. Note that in this approach, the modulus of 


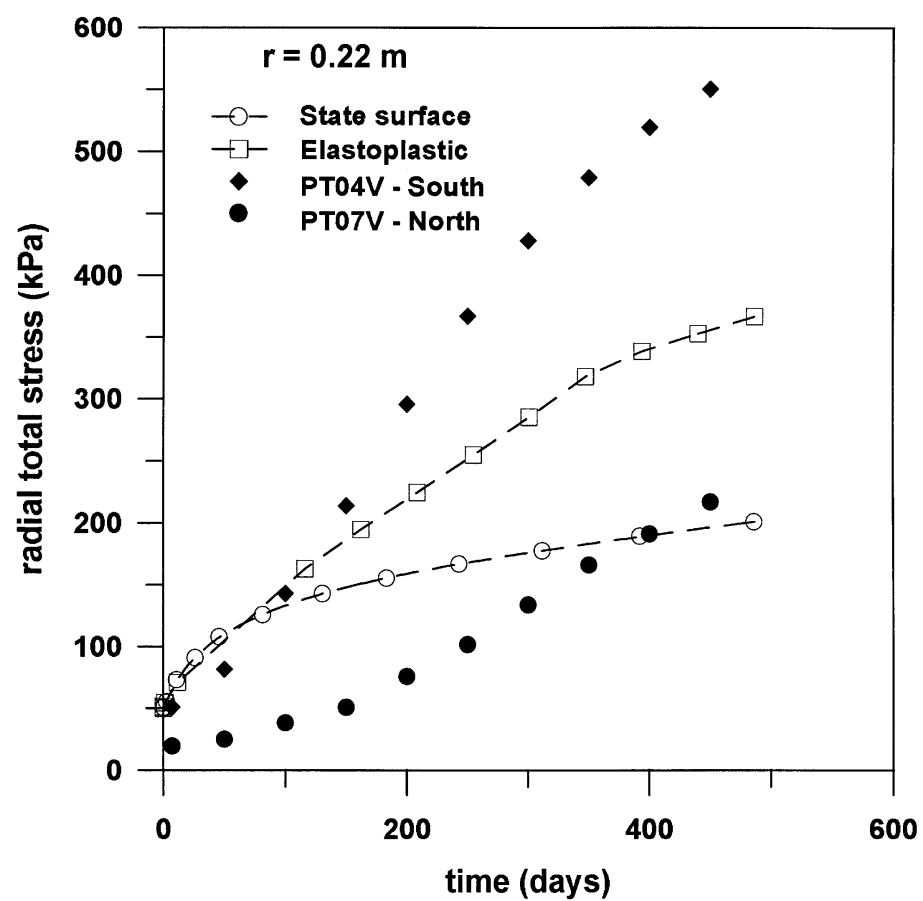

Figure 17. Total radial stresses measured in two sensors located at $r=0.22 \mathrm{~m}$ and model results

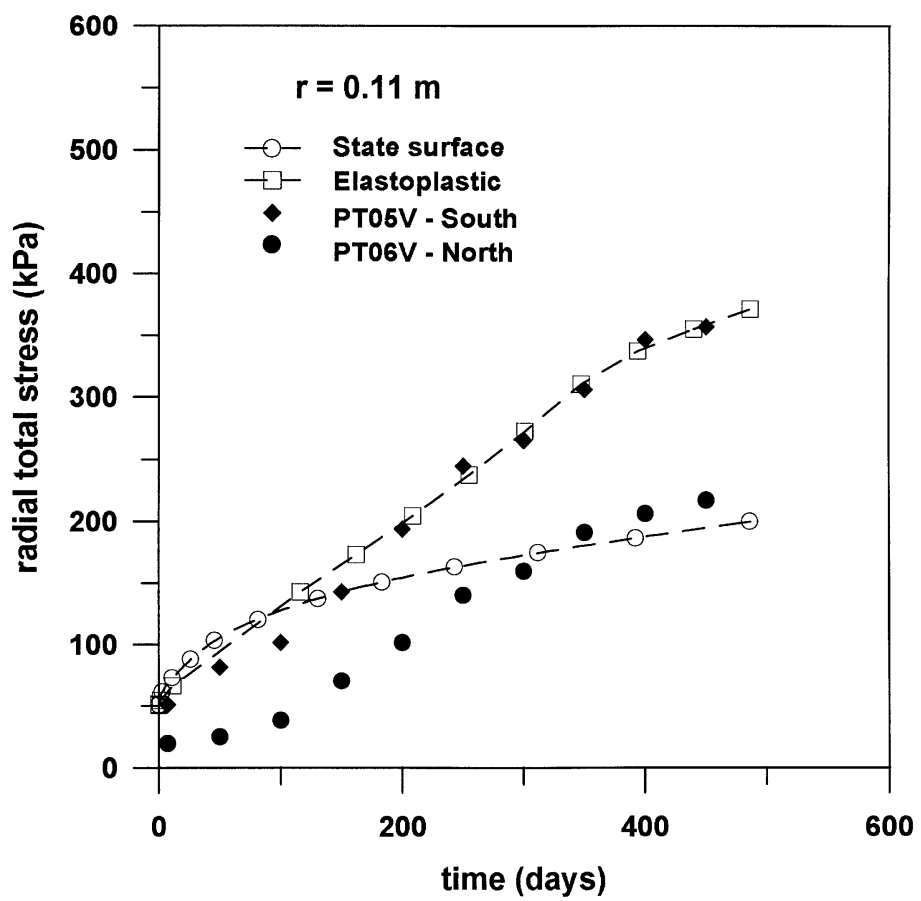

Figure 18. Total radial stresses measured in two sensors located at $r=0 \cdot 11 \mathrm{~m}$ and model results 

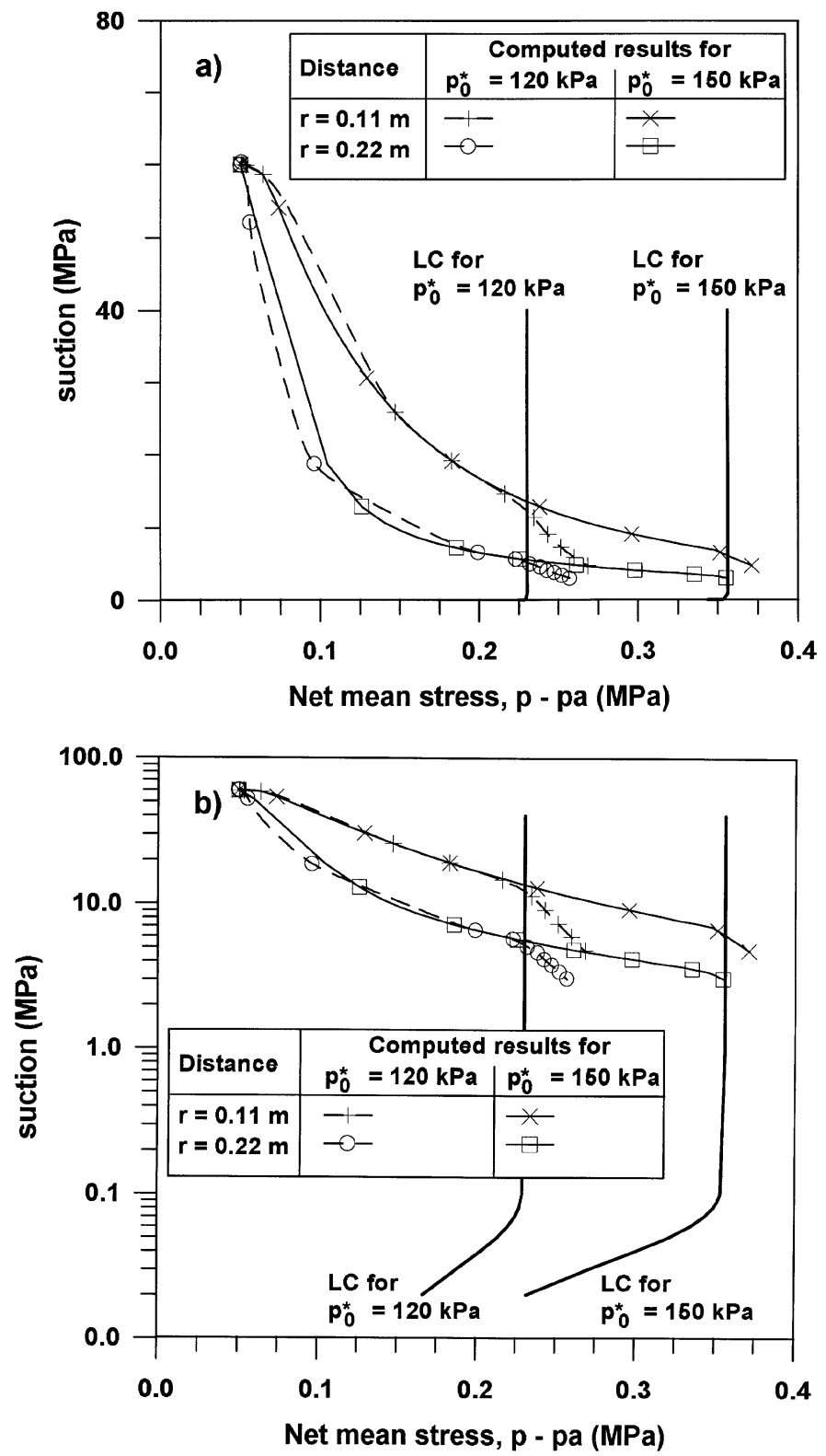

Figure 19. Suction-net mean stress paths for the elastoplastic approach. (a) Suction plotted in log scale. (b) Suction plotted in natural scale

volumetric compressibility is directly obtained through differentiation of the state surface for void ratio (equation (10)).

The elastoplastic results are qualitatively different. Computed stresses increase of a constant rate during a first stage (the first $350 \mathrm{~d}$ ), and begin to decay later. Radial stresses based on this 


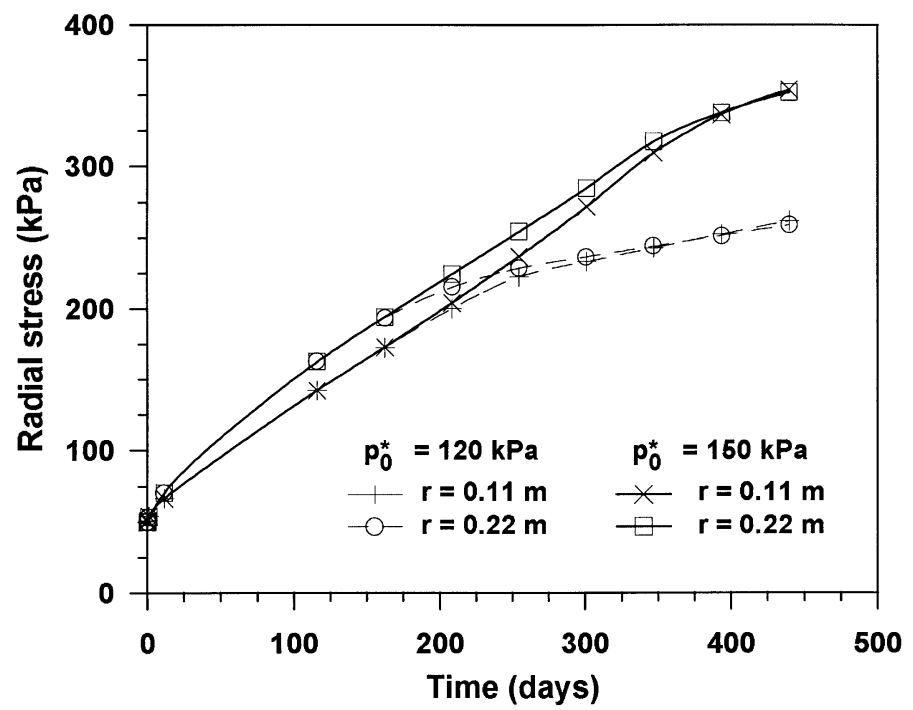

Figure 20. Evolution of computed radial stresses at $r=0.22 \mathrm{~m}$ and $r=0.11 \mathrm{~m}$ for two values of the saturated yield stress $p_{o}^{*}$

model occupy a central position between North and South results for $r=0.22 \mathrm{~m}$ and reproduce more accurately the maximum stresses measured at $r=0.11 \mathrm{~m}$. This behaviour is explained in Figure 19 which shows the suction-net mean stress paths computed for $r=0.22 \mathrm{~m}$ and $r=0.11 \mathrm{~m}$. The figures show also the effect of changing the value of the saturated yield stress, $p_{o}^{*}$ (from $p_{o}^{*}=120 \mathrm{kPa}$ to $p_{o}^{*}=150 \mathrm{kPa}$ ). The initial position of the Loading Collapse yield curves for those two values of $p_{o}^{*}$ has also been plotted in Figure 19.

Before hitting the yield locus, the wetting path followed by the fill lies within the elastic region postulated in the model. Along this part of the $(p, s)$ path the soil behaves elastically and its compressibility does not change since constant elastic parameters have been adopted. This explains the constant rate of radial stress development in earlier times during the test. However, when the stress path reaches the current yield locus, irreversible volumetric compressive strains begin to develop and net mean stresses develop slowly as suction decreases. A 'kink' in the $(p, s)$ stress path is therefore obtained when the LC yield curve is reached. The overall soil compressibility increases and this is also reflected in computed radial stress beyond some time (Figures 17 and 18).

The relevance of the saturated initial yield net mean stress, $p_{o}^{*}$, is further illustrated in Figure 20, which shows the computed evolution of radial stresses for the considered radial distances and two values of $p_{o}^{*}$. The smaller elastic region for $p_{o}^{*}=120 \mathrm{kPa}$ implies that the backfill reaches earlier a softening state (collapse conditions) as hydration proceeds. This results in a decaying rate of radial stress development beyond a certain time. For $p_{o}^{*}=150 \mathrm{kPa}$, however, most of the fill remains elastic during the simulation performed and this explains the stiffer response of the backfill. Parameter $p_{o}^{*}$ has, therefore, a relevant influence on the results of the elastoplastic analysis.

\section{CONCLUSIONS}

One of the main purposes of the BACCHUS2 hydration in situ test was to provide data for the validation of hydro-mechanical models for partially saturated compacted clay fills. An extensive 
program of laboratory tests of compacted Boom clay powder and compacted mixtures of powder and pellets has provided data on permeability, water retention characteristics and volumetric deformation of the fill under varying suction (or saturation) conditions. Instrumentation of the natural Boom clay deposits near the test emplacement has also provided data to specify initial and boundary conditions of the experiment. Enough information has therefore been obtained to allow a simulation of test performance. Two alternative mechanical models of soil behaviour (state surface description for volumetric deformations and an elastoplastic model) have been compared in the analysis performed.

The existing experimental data base of fill behaviour has allowed the identification of parameters of both approaches. The methodology for parameter identification represents a major part of the modelling effort and has only been outlined in this paper. More details may be found in Reference 12. It can be said that the state surface approach requires less parameters than the elastoplastic counterpart and they are also more readily found.

The analysis of the computed results reveals that the apparently simple phenomenon of fill hydration is in fact a complex coupled processes for the backfill and the immediate natural clay. The plotted stress paths indicate that the fill experiences deviatoric stress reversals whereas in the natural clay a drying-wetting cycle takes place. Comparison between measured and computed evolution of backfill saturation shows a good agreement for the two models used. In addition, the specific description of mechanical behaviour has a very limited effect on saturation changes.

Measured radial stresses within the backfill are markedly non-symmetrical, and this probably indicates non-homogeneous characteristics in the fill, the natural clay or both, which were not intended or, indeed, foreseen during test installation.

Symmetrical conditions were assumed in the analysis but, nevertheless, the comparison between measured and computed radial stresses has provided an interesting insight into the relative merits of the two approaches adopted. Radial stresses derived from the elastoplastic approach develop in time at a rate consistent with measurements. Computed absolute values are close to the average measured values. The elastoplastic approach shows an encouraging potential to model mechanical phenomena within barriers experiencing a progressive hydration. Computed results are, however, critically dependent on some key parameters of the model. The significance of the hardening parameter (saturated yield stress), a parameter which is difficult to estimate in practice, has been presented.

Computed stresses based on the state surface approach present more discrepancies with measured values and, more specifically, with the time development of stresses. The model overestimates stresses in the short term and overestimates them in the long term. This represents a qualitative disagreement with observed behaviour which has been explained by the apparently unrealistic continuous and rapid softening of the soil as hydration proceeds.

A better understanding of phenomena taking place in swelling clay barriers experiencing natural hydration from the host rock has been gained. Also, present modelling capabilities at sample scale (constitutive behaviour) and real scale (field equations) have been verified within the framework of a comprehensive laboratory and 'in situ' testing program. Overall, results are satisfactory and it is believed that the analysis presented in the paper is a positive step towards the development of more accurate models for the prediction of engineered clay barriers performance.

\section{ACKNOWLEDGEMENTS}

The work described has been supported by the Spanish national agency for nuclear waste disposal (ENRESA) and by the EU through Projects FI2W-CT-91-0033 and FI2W-CT-91-0102. 
BACCHUS2 test was performed by the Belgian nuclear energy center, SCK-CEN, under the direction of G. Volckaert. J. Vaunat is the recipient of a fellowship of the Human Capital and Mobility Programme of the EU. Basic research has been supported by the Spanish scientific and technical research agency (CICYT) through research grants PS92-0702 and PB93-0964.

\section{APPENDIX: NOTATION}

\section{$F:$ Force; $\quad L:$ Length; $\quad M$ : Mass; $\quad T:$ Time}

$a, b, c, d$ constant parameters in equation relating void ratio with net stress and suction changes (state surface approach)

$a^{\prime}, b^{\prime}, c^{\prime}, d^{\prime}$ constant parameters in equation relating void ratio with net stress and suction changes (simplified expression; state surface approach)

$A, B \quad$ constant parameters in equation relating unsaturated water permeability with suction

$b_{i} \quad$ body forces in equilibrium equation, $F / L^{3}$

$D, C \quad$ constant parameters in equation relating unsaturated air permeability with suction and void ratio, $\left[\mathrm{C}:\left(\mathrm{L}^{2}\right)\right]$

$e, e_{0} \quad$ void ratio; initial void ratio

$E, F \quad$ constant parameters in equation relation degree of saturation with suction $\left[\mathrm{F}:\left(\mathrm{FL}^{-2}\right)^{-1}\right]$

$G \quad$ elastic shear modulus (elastoplastic model), $\mathrm{F} / \mathrm{L}^{2}$

$G_{t} \quad$ non-linear elastic shear modulus (state surface approach), $\mathrm{F} / \mathrm{L}^{2}$

$H \quad$ Henry's constant $(=0 \cdot 018)$

$K_{t} \quad$ nonlinear elastic modulus of soil compressibility (state surface approach), $\mathrm{F} / \mathrm{L}^{2}$

$K_{\mathrm{w}} \quad$ permeability to water (unsaturated conditions) $\mathrm{I} / \mathrm{T}$

$K_{\mathrm{w}}^{\mathrm{o}} \quad$ permeability to water (saturated conditions), L/T

$k_{s} \quad$ Parameter describing the increase in cohesion with suction (elastoplastic model)

$M \quad$ slope of critical state failure envelope

$n \quad$ porosity

$p \quad$ net mean stres (triaxial stress states) $\left(=\sigma_{1}+2 \sigma_{3} / 3-p_{\mathrm{a}}\right) \mathrm{F} / \mathrm{L}^{2}$

$p_{\mathrm{a}} \quad$ air pressure, $\mathrm{F} / \mathrm{L} 2$

$p_{\text {at }} \quad$ atmospheric pressure, $\mathrm{F} / \mathrm{L}^{2}$

$p^{c} \quad$ reference stress (elastoplastic model), $\mathrm{F} / \mathrm{L}^{2}$

$p_{o} \quad$ current yield net mean stress (for suction $s$ ) $\mathrm{F} / \mathrm{L}^{2}$

$p_{o}^{*} \quad$ current effective mean yield stress (saturated state), $\mathrm{F} / \mathrm{L}^{2}$

$p_{s} \quad$ apparent cohesion in terms of net mean stresses (elastoplastic model), $\mathrm{F} / \mathrm{L}^{-2}$

$p_{\mathrm{w}} \quad$ water pressure, $\mathrm{F} / \mathrm{L}^{2}$

$q \quad$ deviatoric stress (triaxial stress states) $\left(=\sigma_{1}-\sigma_{3}\right) \mathrm{F} / \mathrm{L}^{2}$

$r \quad$ parameter defining maximum soil stiffness (elastoplastic model)

$S_{r} \quad$ degree of saturation

$s \quad$ matric suction $\left(=p_{\mathrm{a}}=p_{\mathrm{w}}\right), \mathrm{F} / \mathrm{L}^{2}$

$v_{\mathrm{a}} \quad$ velocity of air (Darcy), I/T

$v_{\mathrm{w}} \quad$ velocity of water (Darcy), $\mathrm{I} / \Gamma$

$v \quad$ specific volume $(=1+e)$

$\alpha \quad$ parameter of the nonassociated flow rule (elastoplastic model) 
$\beta \quad$ parameter controlling the rate of increase of soil stiffness with suction (elastoplastic model), $\mathrm{L}^{2} \mathrm{~F}^{-1}$

$\gamma_{\mathrm{a}} \quad$ specific weight of air, $\mathrm{F} / \mathrm{L}^{3}$

$\varepsilon_{k l} \quad$ strain tensor

$\varepsilon_{0} \quad$ volumetric strain

$\varepsilon_{v}^{\mathrm{p}}, \varepsilon_{v}^{\mathrm{e}} \quad$ plastic volumetric strains; elastic volumetric strains

$\varepsilon_{q}^{\mathrm{p}}, \varepsilon_{q}^{\mathrm{e}} \quad$ plastic deviatoric strains; elastic deviatoric strains

$\varepsilon_{s}^{\mathrm{e}} \quad$ elastic strains induced by suction changes (elastoplastic model)

$\kappa \quad$ elastic stiffness parameter for changes in $p$ (elastoplastic model)

$\kappa_{s} \quad$ elastic stiffness parameter for changes in suction (elastoplastic model)

$\lambda(s) \quad$ stiffness coefficient for changes in $p$ for virgin states (elastoplastic model)

$\lambda(o) \quad$ stiffness coefficient for changes in $p_{o}^{*}$ for virgin states (elastoplastic model)

$\mu \quad$ dynamic viscosity of air, $\mathrm{F} \mathrm{T} \mathrm{L}^{2}$

$v \quad$ Poisson's ratio

$\rho_{\mathrm{a}} \quad$ mass density of air, $\mathrm{M} / \mathrm{L}^{3}$

$\rho_{\mathrm{w}} \quad$ mass density of water, $\mathrm{M} / \mathrm{L}^{3}$

$\sigma_{1}, \sigma_{2}, \sigma_{3}$ total principal stresses, $\mathrm{F} / \mathrm{L}^{2}$

$\sigma_{i j} \quad$ total stress tensor $\mathrm{F} / \mathrm{L}^{2}$

$\sigma_{i j}^{*} \quad$ net stress tensor $\left(\sigma_{i j}=\sigma_{i j}-p_{\mathrm{a}} \delta_{i j}\right) \mathrm{F} / \mathrm{L}^{2}$

\section{REFERENCES}

1. A. Gens, E. E. Alonso, A. Lloret and F. Batlle, 'Analysis of construction and consolidation of earthdams', Proc. 16th Congress on Large Dams, Vol. (28), San Francisco, 1988, pp. 1371-1386.

2. E. E. Alonso, A. Gens and A. Lloret, 'Double structure model for the prediction of long-term movements in expansive materials', in Beer, Booker and Carter (eds.) Comp. Methods Adv. Geomechanics, Balkema, 1991, pp. 541-548.

3. A. Lloret and E. E. Alonso, 'Unsaturated flow analysis for the design of a multilayer barrier', Proc. 13th ICSMFE, New Delhi, 1994, pp. 1629-1632.

4. A. Lloret and E. E. Alonso, 'State surfaces for partially saturated soils', Proc. 11th ICSMFE, Vol. 2, San Francisco, 557-562.

5. E. E. Alonso, F. Batlle, A. Gens and A. Lloret, 'Consolidation analysis of partially saturated soils: application to earthdam construction', Proc. 6th Int. Conf. on Numerical Meth. in Geomech. Vol. 2 Innsbruck, 1988, pp. $1303-1308$.

6. A. Gens, E. E. Alonso and A. Josa, 'Elastoplastic modelling of partially saturated soil', in: S. Pietruszcak and G.N. Pande, (eds.), Numerical Models in Geomechanics III, Elsevier ASP, London, 1989, pp. 163-170.

7. E. E. Alonso, A. Gens and A. Josa, 'A constitutive model for partially saturated soils', Géotechnique, 40(3), 405-430 (1990).

8. A. Lloret and E. E. Alonso, 'State surfaces for partially saturated soils', Proc. 11th. ICSMFE, Vol. 2: San Francisco, 1985, pp. 557-562.

9 A. Gens and E. E. Alonso, 'A framework for the behaviour of unsaturated expansive soils', Canad. Geotech. J., 29, 1013-1032 (1992).

10. F. Bernier and B. Neerdael, 'Overview of in situ thermomechanical experiments in clay: concept, results and interpretation', Engng Geol., 41, 51-64 (1996).

11. G. Volckaert, F. Bernier and M. Dardaine, 'Demonstration of the in situ application of an industrial clay-based backfill material (BACCHUS2)', SCK-CEN Report R-3011, 1993.

12. G. Volckaert, F. Bernier, E. Alonso, A. Gens, J. Samper, M. Villar, P. L. Martin-Martin, J. Cuevas, R. Campos, H. Thomas, C. Imbert and V. Zingarelli, 'Thermal-hydraulic-mechanical and geochemical behaviour of the clay barrier in radioactive waste repositories (model development and validation)', Final Report to Contracts $F 12$ W $/ C T 90 / 0033$ and F12W/CT91/|0102, European Commission, EUR 16744EN, 1996.

13. G. Volckaert, P. De Cannière, P. Hooker, V. Fioravante, P. Grindrod and M. Impey, MEGAS: modelling and experiments on GAS migration in repository host rocks', in: B. Haijtink and T. McMenamin, (eds.) Proc. Progress Meeting: Project on Effects of Gas in Underground Storage Facilities for Radioactive Waste (Pegasus project); Report EUR14816: 142-156, 1993. 
14. G. Baldi, T. Hueckel, A. Peano and R. Pellegrini, 'Developments in modelling the thermo-hydro-geochemical behavior of Boom clay and clay based buffer materials', CEC Report EUR 13365/1 and 2 EN, 1991.

15. A. Bone, H. Beckers, R. Beaufays, M. Buyens, J. Coursier, D. de Bruyn, A. Fonteyne, J. Genicot, D. Lamy, P. Meynendonckx, M. Monsecour, B. Neerdael, L. Noynaert, M. Voet and G. Volckaert, '(The HADES demonstration and pilot project on radioactive waste disposal in a clay formation', Final Report to Contract FI1W/0004B, EUR 13581 EN, 1992.

16. E. L. Matyas and H. S. Radhakrishna, Volume change characteristics of partially saturated soils, Géotechnique, 18(4), 432-448 (1968).

17. UPC Geomechanics group, 'Modelling and validation of the thermal-hydraulic-mechanical and geochemical behaviour of the clay barrier', Final Report Contract F12W-CT91-0102, 1995.

18. D. Hilled, Fundamentals of Soil Physics, Academic Press, New York, 1980, 415p.

19. V. Yoshimi and J. O. Osterberg, 'Compression of partially saturated cohesive soils', Inl. Soil Mech. Found. Engng Div., ASCE 89 (SM4), 1-24, (1963) 